\title{
Effort shapes social cognition and behaviour: A neuro-cognitive framework
}

\author{
Luis Sebastian Contreras-Huerta ${ }^{\mathrm{a}, \mathrm{b}, *, 1}$, M Andrea Pisauro ${ }^{\mathrm{a}, \mathrm{b}, \mathrm{c}, 1}$, Matthew A.J. Apps ${ }^{\mathrm{a}, \mathrm{b}, \mathrm{c}, \mathrm{d}}$

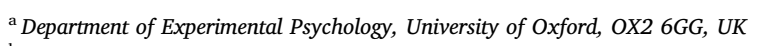 \\ ${ }^{\mathrm{b}}$ Wellcome Centre for Integrative Neuroimaging, University of Oxford, UK

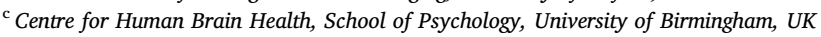 \\ ${ }^{\mathrm{d}}$ Christ Church College, University of Oxford, UK
}

\section{A R T I C L E I N F O}

\section{Keywords:}

Effort

Motivation

Social cognition

Empathy

Theory of mind

Prosocial behaviour

\begin{abstract}
A B S T R A C T
Theoretical accounts typically posit that variability in social behaviour is a function of capacity limits. We argue that many social behaviours are goal-directed and effortful, and thus variability is not just a function of capacity, but also motivation. Leveraging recent work examining the cognitive, computational and neural basis of effort processing, we put forward a framework for motivated social cognition. We argue that social cognition is demanding, people avoid its effort costs, and a core-circuit of brain areas that guides effort-based decisions in nonsocial situations may similarly evaluate whether social behaviours are worth the effort. Thus, effort sensitivity dissociates capacity limits from social motivation, and may be a driver of individual differences and pathological impairments in social cognition.
\end{abstract}

\section{A framework for goal directed social behaviour}

Motivated, goal-directed behaviour (see Table 1) is defined as how willing an individual is to incur a cost, such as exert effort, to obtain a benefit, such as economic or food rewards (Le Heron et al., 2017; Pessiglione et al., 2018; Salamone and Correa, 2018). Being motivated and putting in effort is vital for the success of an individual, with reduced motivation linked to poorer mental and physical health, lower educational outcomes, and long-term unemployment (Esposito et al., 2014; Le Heron et al., 2017; Van Reekum et al., 2005). Yet one of the most important facets of goal-directed behaviour is rarely discussed: many acts occur during social interactions that are effortful. Whether opening the door for a stranger, or trying to predict the moves of an opponent while playing chess, these are social and goal-directed behaviours requiring cognitive and physical exertion. Social behaviours and cognitions must therefore be bound by similar principles and constraints as other effortful acts.

Here, we outline an account of goal-directed, effortful social cognition and behaviour. We place social cognition under the lens of the latest theoretical and empirical work on the psychological, computational and neural basis of effort. In doing so we demonstrate how many aspects of key social processes can be viewed in a different light. We provide a framework for how motivation may shape social behaviour and how using the tools of effort-based decision-making can provide insight into social cognition. In addition, we also point to how research deploying effort-based decision-making approaches has already helped us to better understand aspects of social behaviour and how it may be vital to understand understand social effort, to explain variability in and impairments to - social behaviour.

\section{Goal-directed social motivation}

\subsection{Social acts are effortful}

Goal-directed actions are only performed if someone is sufficiently incentivised by a reward, such as money, food or social approval, and willing to suffer the costs required to obtain it, such as exerting the necessary effort. Typically people are averse to exerting effort (Apps et al., 2015a; Kool and Botvinick, 2018; Kurzban et al., 2013). If two acts are associated with the same reward, most species will choose the least demanding (Le Heron et al., 2017; Salamone and Correa, 2018). Although there are exceptions (Inzlicht et al., 2018), this aversion to effort has been robustly demonstrated for a range of physically and cognitively demanding tasks, and is a key factor in how people decide what activities to pursue (Apps et al., 2015a; Chong et al., 2017; Kool and Botvinick, 2018; Schmidt et al., 2012; Westbrook et al., 2013).

We contend that many social behaviours also require the exertion of effort (Lockwood et al., 2017a; 2017b). From strategic social

\footnotetext{
* Corresponding author.

E-mail addresses: luis.contrerashuerta@psy.ox.ac.uk (L.S. Contreras-Huerta), m.a.pisauro@bham.ac.uk (M.A. Pisauro), m.a.j.apps@bham.ac.uk (M.A.J. Apps).

${ }^{1}$ Equal contributions.
} 
Table 1

Glossary.

\begin{tabular}{|c|c|}
\hline Apathy & A quantifiable reduction in goal-directed behaviour. This can be trait like in healthy, and more severe in clinical, populations \\
\hline Automatic/ Habitual behaviours & Actions triggered by a specific stimulus that arise without an explicit evaluation of the rewards and costs associated to it \\
\hline Benefit / Reward & $\begin{array}{l}\text { A positive outcome that incentivises and increases the chances of a goal-directed behaviour being performed. Many stimuli can serve as } \\
\text { rewards, such as money or food, or social stimuli including smiling, increased reputation or social approval }\end{array}$ \\
\hline Capacity & $\begin{array}{l}\text { Individual proficiency to perform in a task. It is the upper bound of how well a task can be performed under optimal conditions. Capacity can } \\
\text { vary based on regularity of training or learning. Future research will need to shed light on how it might differ between different social } \\
\text { processes and between social and non-social contexts }\end{array}$ \\
\hline Common-Currency Hypothesis & $\begin{array}{l}\text { Hypothesis claiming that the representation of reward value is computed using a unique scale for all reward types (social and non-social) } \\
\text { across the same brain regions. }\end{array}$ \\
\hline Effort & $\begin{array}{l}\text { The perception of how physically or mentally demanding a task is. Such perceptions are subjective - what one person finds effortful and } \\
\text { avoids, another does not - and serve as a cost when choosing whether to act }\end{array}$ \\
\hline Effort discounting & $\begin{array}{l}\text { A phenomenon in which the rewards associated with a behaviour are devalued by the effort required to obtain them. When two actions are } \\
\text { associated with equal rewards, typically the less effortful act is chosen }\end{array}$ \\
\hline Empathy & Ability to share and comprehend the affective states of other people \\
\hline Goal-directed behaviour & $\begin{array}{l}\text { Actions that are aimed at obtaining a goal or rewarding outcome. Such behaviours are executed after deliberation over the costs and benefits } \\
\text { of performing the required actions }\end{array}$ \\
\hline Motivation & The willingness to engage in a goal-directed behaviour as a function of cost-benefit evaluations \\
\hline Prosocial behaviour & Acts that benefit others at a personal cost \\
\hline Social motivation phenotypes & $\begin{array}{l}\text { A person's profile of how sensitive they are to the costs or benefits associated with different social behaviours or mental processes. E.g. two } \\
\text { people who show similar social behaviours may do so because of different weightings on how effort averse or incentivised by rewards they are }\end{array}$ \\
\hline Subjective value & $\begin{array}{l}\text { A value that arises following a weighing up of the costs (effort) and benefits (reward) of performing a given act for a particular outcome. Such } \\
\text { valuations guide decisions of whether to perform an act or not. The idiosyncratic representation of rewards and efforts makes such valuations } \\
\text { highly subjective }\end{array}$ \\
\hline Task demand & The objective level of difficulty of a task e.g. the number of items that must be held in mind or the level of force that must be exerted. \\
\hline Theory of Mind (ToM) & $\begin{array}{l}\text { Ability to process, interpret and make inferences about the mental states of others in order to explain and predict their behaviour. Its depth } \\
\text { refers to the number of recursive beliefs used to represent others' minds }\end{array}$ \\
\hline
\end{tabular}

interactions, requiring complex inferences about others' beliefs, mental states and preferences (Devaine et al., 2017, 2014; Frith and Frith, 1999; Hampton et al., 2008), through empathising with strangers (Cameron et al., 2019) and to physically demanding competition or cooperation (Le Bouc and Pessiglione, 2013; Lockwood et al., 2017a; 2017b) many social behaviours are goal-directed acts that require people to incur significant physical or cognitive effort costs. Despite this, the role of effort in modulating social behaviour is often overlooked (Chevallier et al., 2012). Yet, with effort aversion a crucial component of goal directed behaviour, many social behaviours are likely to be avoided if they require more effort than people are willing to undertake.

Of course social processes are not always goal-directed. Repeated performances of tasks and increased familiarity with stimuli, can lead to processes becoming habitual (Dickinson, 1985; Dolan and Dayan, 2013; Kahneman, 2011), and as such some social processes may be automatically or habitually performed rather being directed towards a goal. For example, interacting with a highly familiar other may entail many habitual responses, and are performed regardless of their effort costs. Thus, the same cognitive process (e.g. theory of mind) may at times be habitual and at others goal-directed. Here, given the importance of goal-directed acts, we discuss the prominent role that effort costs would have in shaping social cognition and behaviour when they are goaldirected.

\subsection{Capacity and motivation modulate social behaviour}

Goal-directed behaviours rely on both capacity and motivation. To succeed people must not only have the cognitive and motor skills to complete a task, but also be willing to perform it. However, one's capacity to succeed at a goal-directed behaviour and one's motivation to undertake it can be, in principle, orthogonal (Apps et al., 2015a; Bonnelle et al., 2014; Chong et al., 2017; Kool and Botvinick, 2018; Westbrook et al., 2013). Those who have the highest capacity are not necessarily those who are the most motivated and vice versa (Fig. 1). For this reason, research on goal-directed behaviour examines whether people will choose to perform a level of task difficulty for a particular magnitude of reward, rather than only measuring performance at the underlying cognitive or physical task (Box 1 ). In such research, there is a significant amount of systematic variability in how willing people are to choose highly difficult or effortful behaviours for rewards, even when controlling for people's capacity at the task (Bonnelle et al., 2014; Chong et al., 2017; Klein-Flügge et al., 2016; Kool and Botvinick, 2018; Pessiglione et al., 2018). This includes a range of studies operationalizing cognitive effort as task switching, switches of peripheral attention and working memory. Even though these tasks differ in the cognitive operations required, in all of these cases most people need a bigger incentive to perform a more demanding version of the same task (Apps et al., 2015a; Bonnelle et al., 2014; Chong et al., 2017; Kool and Botvinick, 2018; Vassena et al., 2014; Westbrook et al., 2013). This demonstrates that people's willingness to perform an effortful behaviour is subjective, and partially orthogonal to their capacity to succeed at it.

When applied to social cognition and behaviour, disentangling motivation and capacity can prove powerful. If a social behaviour is physically effortful, or a socio-cognitive process mentally demanding, people who are perfectly able to perform such acts may simply choose not to because they lack the required motivation (Fig. 1A). This may be because the effort is too demanding, or because the incentives of the social behaviour are not sufficient for the required effort (Fig. 1B). Although previous research has discussed how social motivation might differ between people in terms of reduced sensitivity to social rewards (Morelli et al., 2015; Ruff and Fehr, 2014; Zaki and Ochsner, 2012), less attention has been devoted to understand how effort aversion shapes such processes. To understand motivation to engage in social processes, we must therefore separately examine how incentivised people are by rewards, and how effortful they find the cognitive or physical demands required to obtain them.

However, research examining social cognition and behaviour typically does not measure motivation. Most studies measure people's accuracy and reaction times (RTs) in a task, implicitly assuming that differences in such measures are driven by differences in capacity. For example, poor performance in understanding others' false beliefs in theory of mind (ToM) tasks is typically inferred to mean reduced capacity in attributing mental states to others (Apperly et al., 2006; Baron-Cohen et al., 1985; Korucu et al., 2017; White et al., 2009). Although this may be true in some individuals in certain tasks, it need not be the case. Motivation significantly impacts on non-social task 


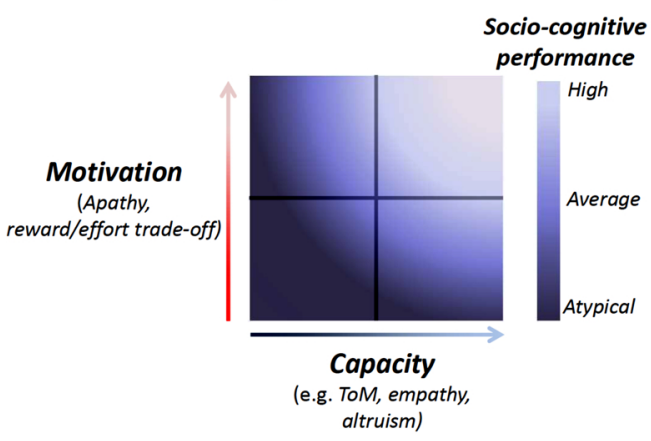

B Effort \& reward sensitivity modulate social task performance

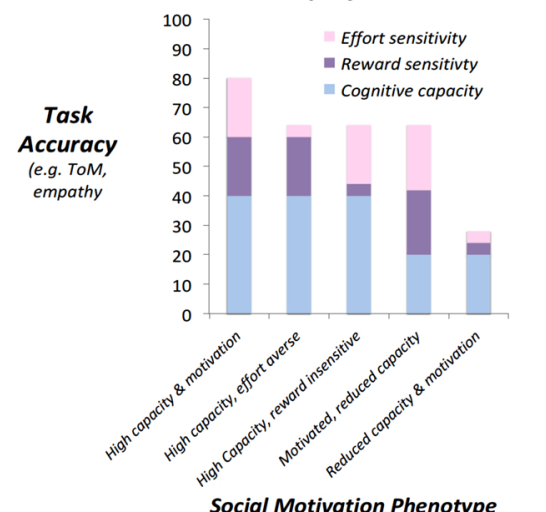

Fig. 1. Motivation shapes social behaviour. (A) Hypothetical relationship between motivation, capacity and performance in a sociocognitive task. The success of goal-directed behaviour is determined by both one's capacity to perform the required cognitive (or physical) processes, but also one's motivation to engage them. Some individuals may express atypical social behaviour because of a reduced capacity in the underlying cognitive mechanisms, whereas others' may do so because of a reduced motivation to engage in that behaviour. (B) Hypothetical individual "phenotypes" of social motivation with different combinations of effort and reward sensitivity, and capacity. This 'apathy' for social behaviour may arise because of a heightened sensitivity to the effort required to perform the task (e.g. engaging in theory of mind is highly cognitively effortful

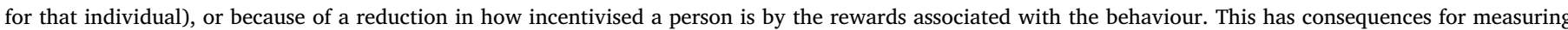

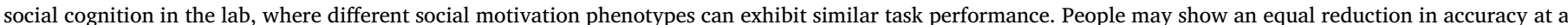
social cognition task, but have different mechanisms underlying the reduced performance.

performance (Kool et al., 2018). It follows therefore, that individual differences in performance on social tasks could also be due to variability in motivation (Fig. 1). Quite often, research involving social tasks does not control rigorously whether variability in social behaviour across healthy people, or more significant disruptions in clinical populations, arise due to reductions in capacity, reward sensitivity, effort aversion, or some combination of them. However, it is plausible that some sub-clinical traits, and more severe clinical dysfunctions, are related to different profiles of motivation, linked to reward incentivisation and effort sensitivity. Previously it has been suggested that motivational impairments are evident in various forms across psychiatric conditions. Such claims have sometimes been made with a suggestion that increased or decreased BOLD signal is reflective of more or less effort being exerted in one group compared to another, e.g. it is more

Box 1

Benefits are devalued by effortful social processes.

\section{BOX.1 Benefits are devalued by effortful social processes}

Trade-offs between effort and reward have recently been conceptualised within neuroeconomic frameworks using computational modelling (Fig.l). In such accounts, rewards are subjectively devalued by effort non-linearly, which is indexed by examining people's choices between low reward, low effort options and higher in reward, but more demanding offers. (E.g. would you be willing to perform a 3-back working memory task for 30 s for $f 1$, or do nothing for 30 s but only receive $f 0.10$ ). By varying the rewards and effort offered to participants, one can quantify what reward is needed for what amount of effort for a person. Typically for a given task, people will devalue the rewards in a similar manner mathematically, but such decisions are subjective. Although there is some debate over the mathematical function that best fits different types of task Chong et al., 2017, Klein-Flugge et al., 2015, typically as the demand of a task increases, the effort costs increasingly devalue the rewards. As a result, people are less willing to put in the effort and work. Such 'reward devaluation' has been demonstrated regardless of whether the task required is physical or cognitive. We argue that the same devaluation of rewards will occur for social behaviours (Fig.II).

Fig.l Social behaviour depends on cost-benefit trade-offs

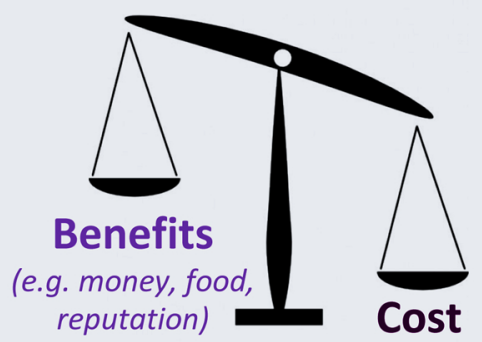

(cognitive or physical effort)
Fig.ll Effortful social acts subjectively devalue rewards

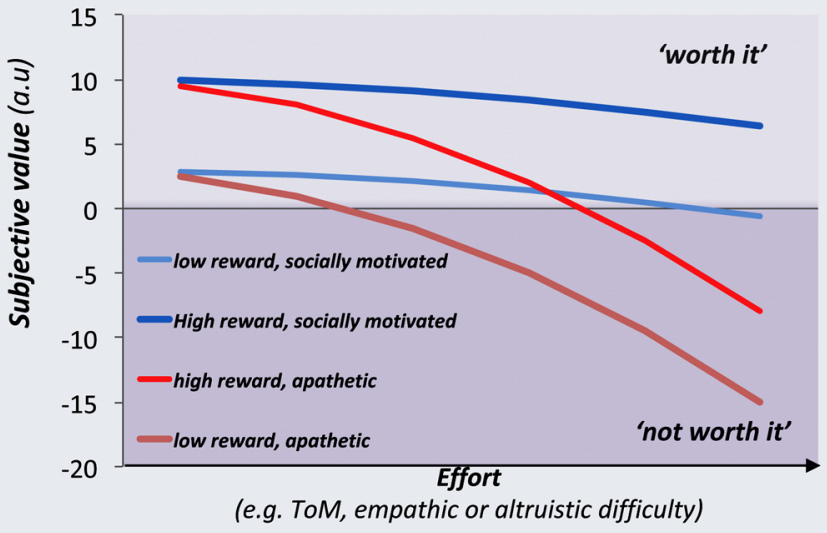

Effortful social processes such as theory of mind or empathy may similarly serve as a cost, devaluing the benefits of performing a social behaviour. Likewise, if being altruistic and helping someone out is physically demanding, this effort may devalue rewards.

Such the devaluation of rewards by effort in social situations will also vary considerably between people. Socially motivated people may need only a small reward to perform even highly demanding social behaviours, whereas apathetic people may need a large incentive to perform even low demand social acts. By varying the demands of a task, and the incentives on offer, it may be possible to identify how motivated people are to engage in socio-cognitive processes, rather than just their examining their performance at a task. 
effortful for the patient group, indicated by increased BOLD signals. However, it is important to stress that a rigorous measure of motivation must be obtained at the behavioural level, and a proxy neural measure, i.e. BOLD activity, is unlikely to uniquely covary with motivation. As such, directly measuring reward and effort-sensitivity using decisionmaking tasks will be more fruitful for dissecting motivational impairments from capacity deficits.

\subsection{Weighing effort costs against rewarding benefits in social interactions}

How do we investigate people's sensitivity to effort? Studies in cognitive psychology and neuroscience typically require participants to make a choice. Participants are asked if the effort required for a level of task demand is "worth it" for an offered amount of reward (Bonnelle et al., 2014; Chong et al., 2015; Kool and Botvinick, 2018; Pessiglione et al., 2018; Westbrook et al., 2013). The effort required serves as a cost, devaluing the reward offered. As such, if the subjective value of an offered reward for a given amount of effort is lower than an alternative - such as no effort, for a lower reward - it will be declined and people will refuse to engage in the associated behaviour. In most studies, a number of other costs are controlled for, to ensure that it is in fact the effort that participants are averse to and not a confounding factor. For instance, participants must be equally able to obtain the rewarding outcomes at all levels of difficulty, ensuring that choosing a more effortful option is not also a risky choice. Similarly, the effortful "offer" and the "alternative" lower or no effort offer must also lead to the same length of delay before an outcome, such that choices are not driven by temporal discounting of rewards (Critchfield and Kollins, 2001). Even when controlling for these other costs, effort discounting is robust, people simply require a bigger incentive to perform a more effortful task (Apps et al., 2015a; Chong et al., 2017).

In social psychology and neuroscience, such tasks designs have not always been employed. Even though there has been an increasing interest in understanding social motivation over the last decade, most of this research has focused on sensitivity to social rewards (Chevallier et al., 2012). The notion being that some personality traits or clinical symptoms might relate to a specific deficit in how incentivised people are by social rewards, relative to other primary or secondary reinforcers. Indeed, there is growing evidence that individuals on the autism spectrum show a reduced sensitivity to social rewards compared to neurotypicals, with social reward sensitivity also negatively correlating with autistic traits (Chevallier et al., 2012; Dubey et al., 2018). This work highlights the importance of social motivation, but only examines one side of the effort-reward trade-off. While differences in sensitivity to rewards are certainly important to drive motivation, differences in effort discounting can be crucial too. Indeed, there is significant evidence that one's sensitivity to monetary rewards, can be separated from one's sensitivity to effort, both psychologically and neurally (Le Heron et al., 2018; Varazzani et al., 2015), highlighting a need to measure them independently to understand the willingness to engage in social acts.

It is also worth noting that for many social behaviours costs other than effort can be associated with a choice. A considerable body of empirical and theoretical research has examined how different kinds of cost/benefit trade-offs have evolved to influence and generate pro-social and altruistic behaviours (de Waal, 2008d; Fehr and Camerer, 2007; Fehr and Fischbacher, 2003; Kitcher, 1993; Kurzban et al., 2013). This include studies of prosocial behaviours involving monetary losses (Berg et al., 1995; Forsythe et al., 1994; Guth et al., 1983; Kahneman et al., 1986; Nash, 1950), physical pain (Crockett et al., 2014; Hein et al., 2010; Volz et al., 2017) or social punishments linked and reputational motivations (Roberts, 1998; Zhan et al., 2019) while acting in order to obtain a benefit or prevent a loss for another person. Incurring these costs may be important, because they increase fitness by strengthening social ties. While this literature has elucidated many aspects of how people behave in the face of these trade-offs, very little work has measured people's motivation to exert effort for another's benefit. Furthermore, in most of these studies the costs associated with a given choice can be incurred with minimal cognitive or physical exertion meaning that the impact of effort on such behaviours is unclear. Thus, controlling for capacity and measuring the motivation to exert effort needs to be studied, both in isolation, and also in terms of impact on how other altruistic costs are processed in order to understand the boundaries of prosocial behaviours.

\subsection{Energising and persisting through sustained social demands}

A key aspect of research examining motivation is that not only does the initial choice to exert effort matter, but once that choice has been made, an act must be energised - one must exert sufficient effort into the action in order to achieve a goal (Inzlicht et al., 2018; Le Bouc and Pessiglione, 2013; Lockwood et al., 2017a; 2017b; Manohar et al., 2015; Pessiglione et al., 2018; Shenhav et al., 2017). There is evidence that the cognitive and neural mechanisms that underpin the initiation and energisation of behaviours are partially separable (Manohar et al., 2015; Pessiglione et al., 2018; Schmidt et al., 2012). Hence, an individual may be willing to choose a demanding behaviour, but this may not carry through to being highly invigorated when undertaking the effortful act itself. For physical effort this means both choosing to do a behaviour, and then exerting the required force or energy, such as lifting heavy boxes to help a friend move to a new house (Lockwood et al., 2017a; 2017b). For mental effort, this may mean an analogous process of increasing the gain or signal-to-noise in the system that underlies the appropriate cognitive control processes (Kool and Botvinick, 2018; Manohar et al., 2015; Shenhav et al., 2017). A failure to do so would result in poor task performance. The same principles will apply for the cognitive processes engaged during social interactions - making them mentally effortful. Therefore, without being incentivised to exert effort and actually energise the cognitive processes required to successfully complete a task, people may inaccurately perform socio-cognitive processes, regardless of their capacity at those processes.

In addition to a single energisation of an action, many goal-directed behaviours are extended over time and require multiple acts and effortful exertions in order to obtain a desired outcome. Thus, the intention to initiate an effortful behaviour, the energisation of each individual act, and the ability to persist and sustain motivation are all crucial for successful behaviour. Indeed there is considerable evidence that behaviour can be significantly affected by factors such as fatigue (Kurzban et al., 2013; Meyniel et al., 2013; Müller and Apps, 2018). Theoretical and empirical accounts suggest that as fatigue rises it inflates the costs of performing the same level of effort or task difficulty (Marcora, 2009; Massar et al., 2018; Müller and Apps, 2018). As such even if initially motivated and indicating a willingness to exert effort, fatigue can induce people to exert effort less as time passes, either by choosing not to exert effort in the first place or by failing to energise the chosen action.

Why would this matter for social behaviours? Most social interactions are not one-shot and most of our social goals extend over significant time periods. To achieve goals during competitive, cooperative, altruistic or antisocial interactions requires people to mobilise resources to perform series of individual acts, and to sustain the energisation of such acts over an extended period of time. Such a notion is important for interpreting the findings of much research, as failures at tasks over extended periods of time may be due to fatigue (Müller and Apps, 2018) rather than reduced capacity limits. As will be discussed in later sections, prolonged social interactions can have similar impacts on behaviour as exerting effort in extended, non-social tasks. While it is currently unknown whether effort is perceived differently or whether fatigue builds up in different ways in social vs non-social contexts, it is not possible to ignore the impact that effort might have both on our willingness to initiate a social behaviour but also on how we sustain that effortful exertion over extended social interactions. By examining 
the value people ascribe to a social behaviour, their subsequent willingness to energise social acts, and how they sustain that motivation over time, we may be able to gain new insights into how influential effort can be in social behaviours and how it differs from non-social behaviours.

\section{Prosocial effort}

Although decades of research have used a variety of different methods to assess how prosocial people are, including self-reports and economic games, until recently effort had largely not been manipulated experimentally. Yet the definition of altruism - acts which benefit other people at a personal cost - parallels that of goal-directed behaviours. Both altruistic and self-benefitting acts often come at a personal effort cost, but prosocial acts differ in that the immediate benefit is to obtain a reward for another person, rather than oneself. For example, helping one's colleague out at work may require the exertion of considerable cognitive or physical effort. Being averse to indicate a willingness to help by exerting effort, or failing to sufficiently energise the helpful act, will lead to individuals failing to act altruistically. How incentivised people are during interactions is modulated by contextual factors such as social approval, reputation management or reciprocity as shown across a variety of economic games (Camerer et al., 2004; Cutler and Campbell-Meiklejohn, 2019; Frith and Frith, 2010; Hampton et al., 2008; Lee and Seo, 2016; Yoshida et al., 2008). However, what is less well understood is how people choose to exert effort for others benefit.

\subsection{People avoid effortful prosocial behaviours}

In many circumstances people are prosocial even towards complete strangers. For instance, people are more averse to others' harm than they are to their own (Crockett et al., 2014) and a large proportion of people will forego money to make charitable donations (Cutler and Campbell-Meiklejohn, 2019; Imas, 2014). However, tests of such prosociality are often in contexts where people do not have to put in much effort, which differs from real-world settings where helping others can require performing physically or mentally challenging tasks. Recently, Lockwood et al. (2017a; 2017b) demonstrated that people will perform prosocial acts, but highlighted how influential effort costs are. They used an effort-based decision-making paradigm that paralleled nonsocial effort based tasks (Chong et al., 2017). Participants chose between 'working' for different levels of reward (2-10 credits), which required physical effort (30-70\% of their own maximum grip strength on a handheld dynamometer), or 'resting', which required no effort but was associated with low reward (1 credit). What was different about this study was that on half of the trials participants would receive the reward themselves, but on the other half the act was prosocial, and the rewards would be delivered to an anonymous other. This was a real economic decision, with participants required to put in a physical effort every time they chose to, in order to obtain a financial bonus for participating.

Using this design, it is possible to dissociate how effort sensitive and reward sensitive people are by examining how willing they were to choose to work, as a function of the grip force and credits. Moreover, using this design it was also possible to control for differences in capacity - maximum grip strength - ensuring that variability in choice behaviour between people depended on differences in the willingness to put in effort to obtain rewards. Thus, reward and effort sensitivity could be examined for both self-benefitting or altruistic acts.

Lockwood et al. (2017a,2017b) found that at lower effort levels, people were almost equally willing to work to obtain rewards for themselves and the stranger, but at higher levels people became more prosocially 'apathetic', taking the no effort option and choosing to 'rest' more for other than self (Fig. 2A). Computational modelling revealed that this arises because people devalue rewards parabolically by physical effort (Chong et al., 2017; Hartmann et al., 2015; Lockwood et al. (2017a; 2017b), leading to greater devaluation when the effort is large. Small differences in effort sensitivity to obtain a reward for someone else compared to oneself are amplified when the effort increases (Fig. 2B). Such aversion to efforts which benefit others also extends to charitable donations (Imas, 2014). We donate more readily when it is easy to do so. Moreover, Lockwood and colleagues showed that even if the other person is not a completely anonymous stranger, people were still less willing to work for them compared to themselves, suggesting that prosocial effort aversion can override concerns about reputation which have significant effects in other types of economic games (Cutler and Campbell-Meiklejohn, 2019). Without examining effort, and parametrically varying costs and benefits independently, the same conclusions would not have been able to be drawn about prosocial behaviour. Specifically, people are much less motivated to choose to benefit others when the effort required is high.

\subsection{Superficiality when energising prosocial behaviours}

The advantage of many effort-based decision-making tasks is that once an individual has made a choice to exert effort, they are then required to perform the action chosen. As a result, it is possible to measure how much energy is actually put in, and compare it with the effort level required. The mismatch between the effort chosen and the effort actually exerted can reveal differences in effort-avoidance between a decision and its implementation, i.e. a degree of superficiality when energising the chosen behaviour.

For instance, in the study by Lockwood et al., outlined in the previous section, it was also possible to examine the amount of force exerted on the grip force device and determine how much energy people were putting into actions which required in principle the same amount of effort. When comparing this metric for self vs other benefiting trials, they were able to reveal a new aspect of altruistic behaviours. Specifically, they found that although people were sometimes choosing to exert high levels of effort for the other person, for the same levels of chosen effort they actually exerted less force for the other person compared to themselves. So even when choosing to help others out at high levels of effort, the behaviour is somewhat superficial and people energise the actions less than if they were working for themselves.

Another study also showed how important it is to measure the energisation of actions to understand how people interact in social groups. Bortolini and colleagues (Bortolini et al., 2017) used a design where the willingness to freely squeeze a grip force device was measured when obtaining rewards for self, ingroup (i.e. fans of the same football team) and neutral individuals (i.e. non-fans). They found that people squeezed to a greater degree for self than the other conditions, but also more so for ingroup than neutral members. Motivation to work for others may therefore be context dependent, changing due to the group affiliation of a beneficiary.

Fundamentally, therefore, effort appears to shape prosocial behaviours. Using designs inspired by effort-based decision-making research has revealed new insights into how people become more selfish - prosocially apathetic and somewhat superficial - when helping others out is highly effortful. By using similar methods in the future, research can begin to ask questions about the boundaries of our moral and prosocial decisions, such as when do people indicate a preference to help others out, but fail because effort is required? In what conditions do people show less of a selfishness for exerting effort and when do other biases in social behaviour become ignored or exacerbated because sustaining effort is too difficult?

\section{Empathising is effortful and costly}

Empathy is typically defined as the ability to understand and share the affective states of others (Cameron et al., 2017; Decety, 2015; Iacoboni, 2008; Lockwood et al., 2015; Singer et al., 2004; Zaki and Ochsner, 2012). Theories of empathy have postulated that it is an 
A
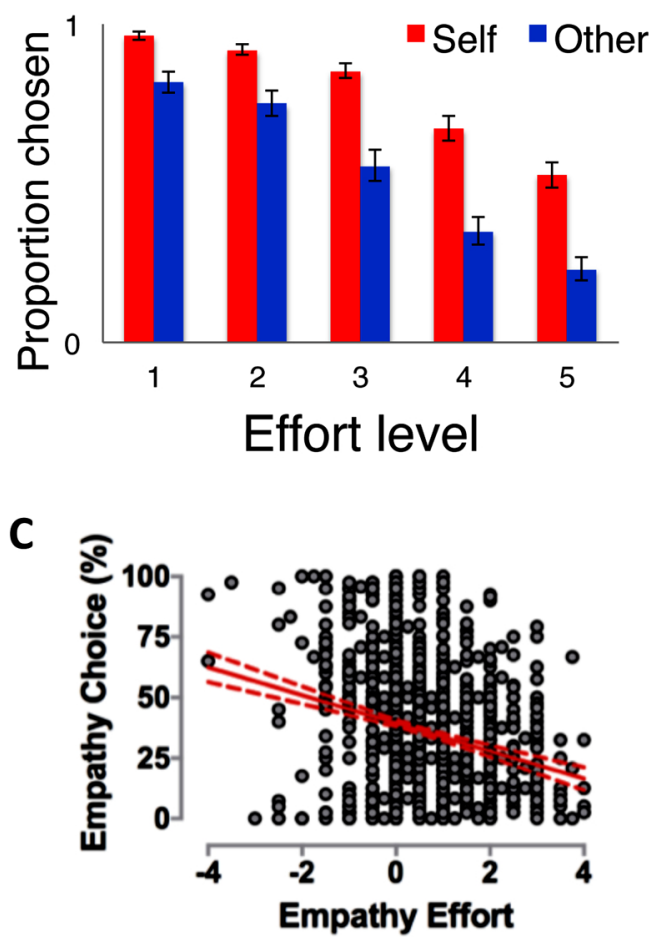

B
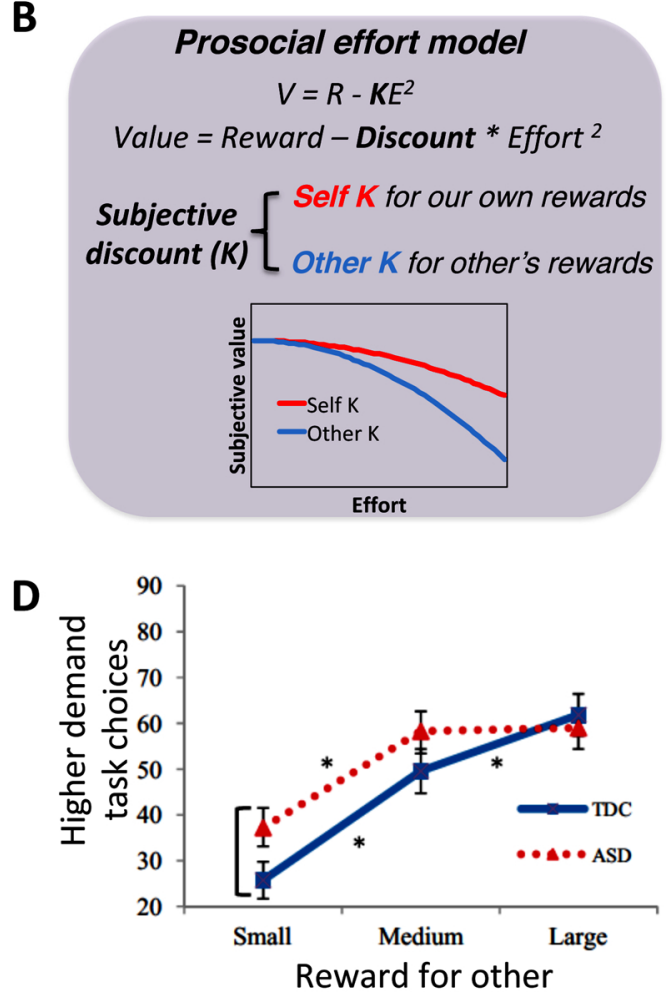

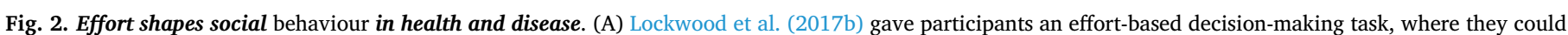

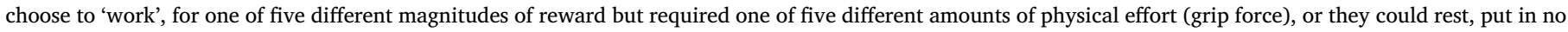

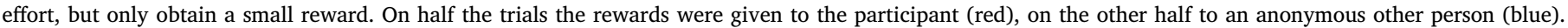

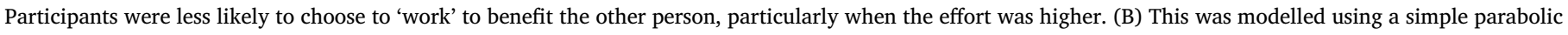

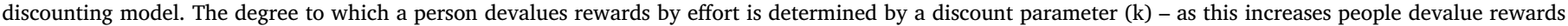

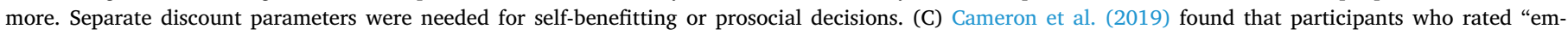

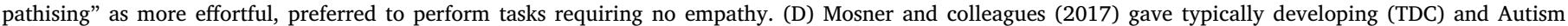

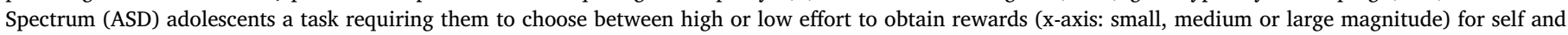

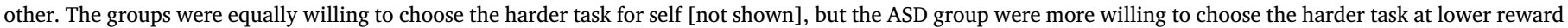
levels than the TDC group for the other person.

automatic behaviour or process whereby seeing another person in distress or experiencing pleasure directly triggers the same emotional state in the observer (Cameron et al., 2017; Lockwood et al., 2017a,2017b; Sonnby-Borgström, 2002). This would imply that variability in how much an individual empathises with another is driven solely by the capacity to do so. However, people do not always empathise with everyone to the same degree in all circumstances, and empathy appears to be malleable. Research in social psychology has shown that many variables, including personality and psychiatric traits, group membership and emotional states, can modulate the extent and the degree in which observers empathise with others (de Vignemont and Singer, 2006d). Crucially, this variability in empathic performance can be seen not only as a fluctuation in people's capacity but also as a difference in people's motivation. Indeed, empathy has been proposed by some authors as having a motivational component (Zaki, 2014). However, here we focused on one aspect in this motivational frame that has been somewhat overlooked. We propose that empathy is an effortful process - in order to engage and successfully empathise with others' affective states, people have to overcome the processing costs associated with representing and reproducing this shared representation. To put it more simply, if empathy was not costly in some manner, why would it be avoided and we not simply always empathise with all other people?

In order to empathise, cognitive and emotional processes are engaged to successfully interact with a target for a period of time. If effort sensitivity or incentives play a role, and empathy was not automatic, we would expect empathy to vary within a person across contexts.
Anecdotally this seems obvious. People empathise with their close friend's suffering or pleasure on a regular basis, but the same person does not empathise with every stranger they meet. Although there may be several possible reasons for this, one possibility is that the empathic processes are effortful and considered 'not worth the effort' in terms of being deployed towards everyone. In fact, a wide range of different studies have shown that empathy is flexibly deployed, particularly in terms of group settings.

There are group biases in empathetic responses to others' emotions, with stronger empathy for ingroup members compared to outgroup (Cikara et al., 2011; Contreras-Huerta et al., 2013; Gutsell and Inzlicht, 2012; Stürmer et al., 2006). However, these biases can be removed. Frequent contact with other groups modulates this effect, with a reduction in this bias for people who have more contact with outgroups (Cao et al., 2015; Swart et al., 2011). The malleability of our tendency to empathise suggests the possibility that they may be goal-directed processes, avoided due to their effort costs but undertaken if sufficiently incentivised. Further evidence of this malleability of the willingness to empathise comes from research in groups who typically refrain from empathising with others (Cameron et al., 2017; de Greck et al., 2012d; Schumann et al., 2014). Studies have shown that people with high levels of psychopathic traits tend not to empathise with others (Blair, 2018; Viding et al., 2014). However, when they are instructed explicitly to do so, psychopaths do not show differences in empathy compared with controls (Meffert et al., 2013). This would fit with the notion that people who do not typically empathise, may still have the capacity when motivated to do so. 
The consequences for an individual for empathising with others appear similar to those of other demanding, effortful processes. People become exhausted by social situations in which they have to empathise (Hansen et al., 2018; Klimecki and Singer, 2012; Rothschild, 2006; Cameron et al., 2016), in a similar manner to how they report feeling fatigue after physically or cognitively demanding tasks (Müller and Apps, 2018). It is therefore possible that repeatedly empathising with another incurs a sustained cost that leads to exhaustion. If empathy is an effortful process, people consequently should avoid it. Indeed, studies have shown that when people have the option, they sometimes avoid to engage emotionally with others (Andreoni et al., 2017; Engen and Singer, 2013; Zaki and Cikara, 2015). This could be due to the observer's personal biases, current emotional states, or intentions to also avoid subsequent behaviours triggered by empathising (e.g. prosocial behaviour). However, we argue that it could be also due to effort aversion. Indeed the feeling of exhaustion brought on by empathy may also change how willing people are to empathise. For instance, repeatedly being exposed to the highly distressing emotional states of others leads to compassion fatigue - a reduction in how much an individual empathises with others (Gleichgerrcht and Decety, 2013; Hansen et al., 2018; Cameron et al., 2016). In addition, there is evidence that people avoid engaging in empathising with others if they believe it will cause fatigue (Cameron and Payne, 2011). Although not direct evidence of people making effort-based decisions about whether to empathise or not, it is consistent with empathy coming at a processing cost, that people may choose to avoid.

\subsection{Empathic effort costs are avoided}

A recent study directly tested the hypothesis that people choose to avoid empathising because it is effortful. Cameron and colleagues showed that people rate empathising as effortful, choose to perform an easy task with no affective component rather than empathising, and need incentives to engage in empathy. The authors used a design which matched those of effort-based decision-making tasks (Cameron et al., 2019). Participants were presented with a choice between an easy task for a low reward (describing physical features of strangers) or empathising with the emotional states of strangers for which they could attain a higher magnitude reward. Using a staircase procedure, they were able to estimate how much more money they would need to choose the easy or empathic task. Strikingly, participants required $\$ 0.39$ more on average to choose to empathise rather than choose the easy task. Moreover, people who rated the empathy task as more effortful were less likely to choose to do it (Fig. 2C). Such behaviour suggests that empathy is costly, and devalues the monetary incentives associated with it. Thus, people invest emotional or cognitive resources when they empathise with others that can lead to fatigue and they need to be incentivised in order to overcome the effort costs associated to it. This framework does not account for all the spectrum of behaviours comprised under the banner of empathic feelings. However, it gives a new perspective of this phenomenon, and hypotheses to be tested about empathic efforts influence behaviour.

\section{Cognitively effortful theory of mind}

Crucial for social interactions is the ability to process, interpret and make inferences about the mental states of others. This ability, commonly referred to as ToM (Baron-Cohen et al., 1985; Premack and Woodruff, 1978) is fundamental for healthy social interactions (Hamilton, 2009). Unlike affective aspects of empathy, ToM - and the partially overlapping concept of cognitive empathy - entails complex and multidimensional representations of other people's beliefs, desires and intentions.

Although often debated, there is evidence that like other goal-directed cognitive processes, ToM is not completely automatic (Apperly et al., 2006; Kovács et al., 2010; Samson et al., 2010). Whilst often it is noted that ToM skills may correlate with executive function capacity (Roca, 2016), studies have shown that levels of ToM correlate with levels of effortful control (Korucu et al., 2017). Different lines of research have provided evidence suggesting that understanding others' mental states, involves not only fast, implicit social-perceptual signals, but also slower, explicit, deliberative cognition (Apperly and Butterfill, 2009; Frith and Frith, 2008; Keysers and Gazzola, 2007). Support for such accounts of ToM as cognitively demanding was offered by correlating direct measurements of ToM skills with social-perceptual (face processing related) and reflexive-cognitive (language and reasoning related) abilities measured independently. They showed that both kinds of abilities explain a significant proportion of individual variability in ToM (Meinhardt-Injac et al., 2018). Developmental studies also show that children become able to use implicit and explicit knowledge about other's people beliefs at different ages (Surian et al., 2007) with the latter being more cognitively demanding and deployed more in adults (Apperly et al., 2009). Thus, although still relying on measures of 'capacity' and performance, these results suggest that there is a slower, demanding, cognitive component to ToM, which is likely to be costly.

ToM also putatively involves shifting attention between different people's perspectives (Lin et al., 2010; Meyer et al., 2012) to take another's point of view. Human subjects take longer and are less accurate in indicating that another's perception differs from their own compared to when it is similar. This breaking of the speed-accuracy trade-off is a hallmark of motivated behaviour, where increased vigour and accuracy of cognitive and motor control come when sufficiently incentivised (Manohar et al., 2015). Furthermore, this egocentric bias in perspective taking is increased under time pressure, but can be decreased through incentives (Epley et al., 2004). Cognitive load also appears to diminish people's ability to imagine themselves in another's perspective (Davis et al., 1996) and similar effects are observed in subjects with working memory deficits (Lin et al., 2010). Conversely, taking the perspective of another person has been shown to detract cognitive resources from concurrent behavioural performance (Vorauer et al., 2009) and working memory performance has been shown to be impaired during a competitive task likely to entail some degree of perspective taking (DiMenichi and Tricomi, 2017). All of these results are consistent with the notion that people process others' perspectives by serially and effortfully adjusting from their own, and are only able to do so when they have sufficient cognitive resources and are sufficiently incentivised to employ them. Individual differences in ToM might in fact therefore be explained by differences in motivation to exert effort to represent other's minds in relation to one's own (Conway et al., 2019).

Moreover, ToM requires individuals to learn the statistical properties of other people's behaviours, and create model-based representations of them (Gläscher et al., 2010; Hampton et al., 2008; Lee and Seo, 2016; Yoshida et al., 2008). Computational work examining ToM has aimed at quantifying and modelling the intentions and goals of competitors in the context of strategic games (Yoshida et al., 2008). In such games, one can use simple heuristics to play against opponents, but such a strategy will not be successful, if the other player is using a more complex strategy. However, people are able to use more or less computationally complex and sophisticated strategies depending upon the depth of an opponent's strategy (Camerer et al., 2004; Chong et al., 2016). In such accounts, "depth" refers to the degree of recursiveness of predictions about the other person's next move (Devaine et al., 2017, 2014; Hampton et al., 2008; Yoshida et al., 2008). A first-order depth like a tit-for-tat response - is less computationally complex than a fifth order where inferences are made about the impact of your next move on their moves five steps into the future. The fact that one's ToM "depth" is flexible, suggests that it is not always automatic, and task performance is certainly not always equal to someone's capacity (Devaine et al., 2017, 2014; Hampton et al., 2008; Yoshida et al., 2008). Although more research is needed to demonstrate the extent to which ToM is effortful, the evidence reviewed parallels research investigating mental effort processing which show that more complex reasoning, such as forming 
models of the world (Kool and Botvinick, 2018), requires multiple steps of reasoning that are avoided unless highly incentivised. Similarly, the deployment of ToM processes, which are inherently complex and sophisticated, may be costly and avoided, unless there is an incentive to do it.

\section{Overlapping neural mechanisms for social cognition and motivation}

\subsection{Neural mechanisms guiding the valuation of effort}

Recent developments in our conceptual understanding of effort and motivation, together with computational approaches that precisely quantify it, have allowed a better understanding of the underlying neural mechanisms (Le Heron et al., 2017; Pessiglione et al., 2018; Shenhav et al., 2013). Research in rodents and non-human primates has suggested that several frontal cortex regions, and connected basal ganglia nuclei, are involved in motivating animals to overcome effort costs (Le Heron et al., 2017; Rudebeck et al., 2006a, 2006b; Salamone and Correa, 2018). Similarly, work using fMRI has identified a corecircuit in the human brain that is important for weighing up the costs and benefits of acting, for ascribing a subjective value for putting in cognitive or physical effort, and to invigorating effortful actions (Box 1 ; Fig. 3) (Bonnelle et al., 2016; Chong et al., 2017; Klein-Flügge et al., 2016; Kurniawan et al., 2013; Schmidt et al., 2012; Shenhav et al., 2013; Vassena et al., 2014). This circuit includes dorsal anterior cingulate cortex (dACC) - area $24 \mathrm{c}$ in the cingulate sulcus - the ventral striatum (VS), basolateral amygdala (BLA), ventromedial prefrontal cortex (VMPFC), anterior portions of the insula (AI) and portions of the dorso-lateral prefrontal cortex (DLPFC). When some of these areas are lesioned in homologous regions in rodents it typically results in a reduced willingness to choose to exert effort for higher reward. When the integrity of these regions is disrupted in neurological disorders it can lead to reduced motivation to exert effort and symptoms of reduced motivation (Bonnelle et al., 2016; Le Heron et al., 2017), suggesting a causal link between the function of some of these regions and daily levels of motivation.

Evidence from single-cell recordings highlights that the spiking of neurons in several regions, particularly in the dACC, signals the amount of effort - lever presses - that are required to obtain a reward (Kennerley and Wallis, 2009a; Salamone and Correa, 2018; Walton et al., 2006). Separately, neurons in the same region signal the amount of reward on offer, and a further subset of neurons signal the combined expected value of exerting the effort for reward (Kennerley and Wallis, 2009a). In humans, a range of studies have shown that BOLD signals measured with fMRI in the dACC, AI, VS, BLA, VMPFC and DLPFC covary with both with the amount of effort required on a trial and with the incentives on offer (Chong et al., 2017; Croxson et al., 2009; Klein-Flügge et al., 2016; Müller and Apps, 2018; Pessiglione et al., 2018; Vassena et al., 2014; Westbrook et al., 2019). This correlation is present both in studies in which participants make a choice, and in experiments where participants are simply required to execute different levels of task difficulty, for different levels of reward, without a choice (Apps and Ramnani, 2014; Croxson et al., 2009; Vassena et al., 2014). This suggests that signals in these regions may be value-based and not choice dependent per se. Although there is a whole field of research still examining the exact computations and contributions of these regions to effort processing and motivation, the weight of evidence suggests that this core-circuit makes important contributions to valuing, motivating and deciding whether to exert effort (Fig. 3).

\subsection{An 'asocial' valuation circuit calculating the cost of behaviours}

Studies across a variety of different socio-cognitive processes including empathy, mentalising and prosocial behaviours implicate a strikingly similar set of regions. Across a whole range of very different social cognition tasks, the BOLD signal in the AI, the dACC, the BLA, VS, VMPFC and DLPFC changes with different aspects of social inference and behaviour (Apps et al., 2015b; Lockwood, 2016; Lockwood et al., 2017a;, 2017b; Moll et al., 2005; Morelli et al., 2015; Ruff and Fehr, 2014; Wittmann et al., 2018; Zaki and Ochsner, 2012). There is considerable overlap with the regions outlined above that guide 'self-benefitting' effort-based decisions (Fig. 3). Firstly, this suggests that if these regions make a contribution to social cognition and behaviour, it is not socially specific (Lockwood et al., 2020b) and that they may perform similar computations regardless of whether the information being processed is social or non-social in nature. It has previously been suggested that overlapping responses to social and non-social information in these regions encodes a form of 'common currency' that makes them crucial for feeling what other people are feeling and putting ourselves in the same affective states as others (Ruff and Fehr, 2014; Rushworth et al., 2013; Singer et al., 2004; Zaki and Ochsner, 2012). However, lesions to some of these regions, such as the anterior cingulate sulcus, do not specifically influence social cognition but do affect other non-social processes (Apps et al., 2016; Lockwood, 2016; Wittmann et al., 2018). Moreover, activity in these regions responds in the same manner when processing information about other people or similar information about a computer (Apps et al., 2013; Balsters et al., 2017). It therefore seems unlikely that many of these regions - particularly the AI, the dACC, the DLPFC and the VS play a specific role in
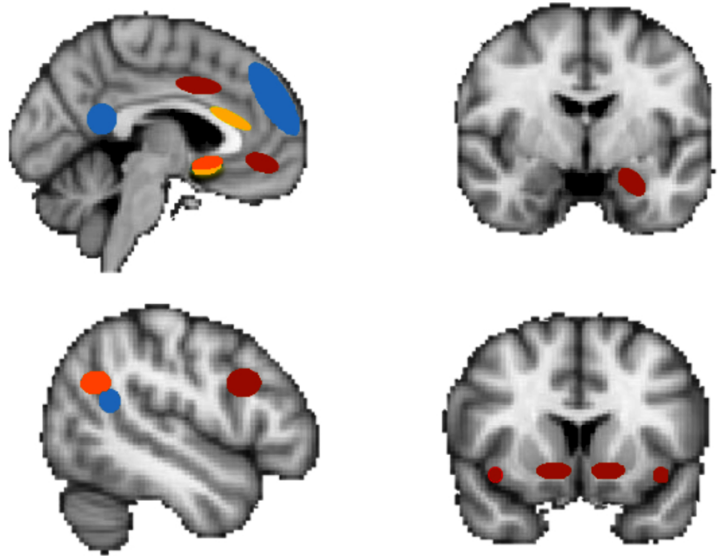

prosocial behaviour

empathy

theory of mind

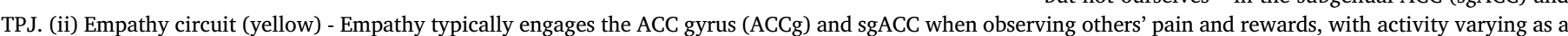

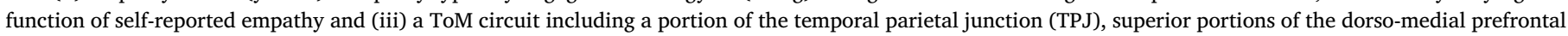
cortex (MPFC), and the precuneus (blue areas).

Fig. 3. Systems guiding effort and social information processing. Electrophysiological work in rodents and non-human primates, and fMRI studies in humans have identified a number of brain regions that are important for weighing up the costs and benefits of acting both in social and non-social contexts. This domain general circuit includes dorsal anterior cingulate cortex (dACC), the ventral striatum (VS), basolateral amygdala (BLA), ventromedial prefrontal cortex (VMPFC), anterior portions of the insula (AI) and the dorso-lateral prefrontal cortex (DLPFC) (maroon areas). This circuit may integrate information from more socially specialised regions, to guide decisions of whether it is worth exerting effort into a social act. Three socially specialised circuits are identified: (i) Prosocial circuit (orange) which responds when people learn to select and energise actions that result in rewards for others but not ourselves - in the subgenual ACC (sgACC) and 
social behaviour that is distinct from their contribution to non-social information processing.

How do the regions outlined above contribute to social cognition? Given the causal and correlational evidence linking them to motivation, we propose that one key contribution of this circuit could be to engage in computations that define the willingness to initiate and sustain effortful behaviours. Crucially this extends to both social and non-social contexts, reflecting their domain-general role in weighing up the costs and benefits of cognitive and physical effort (Chong et al., 2017; Schmidt et al., 2012). These regions may therefore be involved in signalling how effortful and how rewarding a social behaviour is, in calculating the subjective value of that behaviour, and in monitoring the ongoing effort of social behaviours. As such, the same computations may be performed by these regions when calculating and deciding whether it is worth doing a range of social processes. This could include the willingness to empathise, whether people are willing to attempt to understand another's mental states, whether it is worth performing an altruistic act, as well as weighing up the costs and benefits of other nonsocial processes.

Such a notion has some similarities with the 'common currency' and simulation accounts in one sense, suggesting these brain regions may similarly process both social and non-social information (Ruff and Fehr, 2014). But crucially, it is not pointing to these regions putting people into the same cognitive or affective state as the agent they are representing - i.e. we are not suggesting that activity in both social and non-social settings reflects the fact people are empathising or putting themselves in another's cognitive state (Lockwood et al., 2020b). Instead, we suggest that if the role these regions have is to process motivation relevant information, then they will do this regardless of whether people are motivating social or non-social processes. Although previous accounts argued for motivation-relevant information in these circuits, most have yet to consider how the effort cost of a social process is calculated and integrated into a value-based signal. Previous 'common-currency' accounts for social and non-social rewards are therefore insufficient for characterising goal-directed behaviour (Ruff and Fehr, 2014; Zaki, 2014), given the importance that effort costs have in modulating behaviours (Husain and Roiser, 2018; Le Heron et al., 2017). Moreover, implicit in a common-currency account has been the idea that these regions are causally linked to social cognition. For example, disrupting the dACC should prevent people from empathising. However, it seems that in both non-human primates and in humans, disruptions to most of these regions causes changes to non-social behaviour, sometimes sparing social information processing abilities (Apps et al., 2016; Olsson et al., 2020; Rudebeck et al., 2006a, 2006b).

A more parsimonious account of the functions of these regions would be that they compute signals driving social and non-social decisions but in an egocentric reference frame (Apps et al., 2016; Lee and Seo, 2016) - deciding whether it is worth it for ' $m e$ ' to exert effort in this social context. As such, these regions are important for evaluating whether it is worth engaging in goal-directed social and non-social behaviours alike, rather than actually directly for the processes involved in empathising or mentalizing. Importantly such an account suggests that other systems in the brain might be more directly engaged in other-regarding processes such as (i) processing information that underlies the socio-cognitive processes themselves and (ii) when processing the incentives for others that motivate social behaviours. Such claims can be tested by examining neural activity when individuals engage in decisions about whether to perform different levels of difficulty of social tasks for rewards, and compared with similar choices for non-social cognitively or physically effortful tasks.

\subsection{Social specialisation and the effort of social processes}

Whilst we argue that the core-circuit that guides motivation may not respond in a socially specific manner, this is not to say that other connected regions may not play more specialised roles in social cognition (Lockwood et al., 2020, 2020b; Rushworth et al., 2013). Instead, we argue that some regions linked to social information processing are responsible for performing the cognitive processes underlying social behaviour, and that these regions would carry information about how effortful those processes are. In turn, there are other regions that may be involved in signalling information specifically about the benefits that can be obtained from engaging in a social process, either for oneself or for another person. Such information would be integrated in the circuit that guides effort-based decisions, in the same manner as how it integrates information about other physically or cognitively effortful tasks. The connections between areas that are specialised for social processes and areas that guide motivated behaviour, would allow for this circuit to address the question "is this social process worth it?"

In line with these predictions, there are regions which have been argued to be somewhat specialised for empathy and ToM related processes. Neuroimaging studies implicate a portion of the temporal parietal junction (TPJ), superior portions of the dorso-medial prefrontal cortex (areas 8/9; MPFC), and the precuneus (Amodio and Frith, 2006; Döhnel et al., 2012; Frith and Frith, 2010; Mahy et al., 2014; Ochsner et al., 2005; Saxe, 2010; Saxe and Powell, 2006) as responding when making inferences about others' mental states. Intriguingly, there is some evidence that these regions show a greater response the more sophisticated and complex the depth of reasoning that a person is making when predicting another's behaviour (Coricelli and Nagel, 2009; Lee and Seo, 2016). Speculatively, this could reflect the greater response that is required when a more effortful ToM process is being undertaken, in the same manner as how other regions of the brain respond more strongly under greater task demands.

There is evidence of other specialised regions that seem to play important roles in empathy and prosocial behaviours. Parts of the sgACC respond to a greater degree when empathising with others (Lockwood et al., 2016; Moll et al., 2005). This region also appears to be somewhat specialised for social, rather than self or non-social information. Research on prosocial behaviours examining how people learn to select actions that result in rewards for others - but not ourselves - show recruitment of the sgACC (Bortolini et al., 2017; Le Bouc and Pessiglione, 2013; Lockwood et al., 2016; Moll et al., 2008; Wittmann et al., 2018) that varies with trait empathy. Moreover, Bortolini et al. (2017) showed that activity in the sgACC is higher when people were exerting more physical effort to benefit an ingroup rather than outgroup members. A sub-region of the sgACC may therefore be somewhat specialised for social information and may show a greater response when people are empathising to a greater degree, or when exerting more physical effort to benefit others. Speculatively, this would suggest that activity in these regions is modulated by the effort or reward associated with empathising or being prosocial.

Intriguingly, another line of research has identified a different subregion of the anterior cingulate cortex, lying in the gyrus (ACCg), that appears specialised for processing information about others (Apps et al., 2016). Indeed, it processes several different types of motivationally relevant social stimuli (Apps and Ramnani, 2014; Lockwood et al., 2015). When this ACCg region is lesioned, non-social information processing is spared, but the processing of social stimuli is disrupted (Rudebeck et al., 2006a, 2006b). Moreover, this region responds more strongly to the rewards of others and not one's own (Apps et al., 2013; Apps and Ramnani, 2014; Chang et al., 2013; Dal Monte et al., 2020; Lockwood et al., 2015), to the pain of others (Carrillo et al., 2019; Lockwood et al., 2013), and even when learning very simple associations between other people and arbitrary stimuli (Lockwood et al., 2018; Wittmann et al., 2018). The response of this region to others rewards also varies with trait empathy (Lockwood et al., 2015). Taken together, these studies suggest that the ACCg is specialised in processing social information, but also processes the benefits and potentially effort during social interactions. Computations in this region might therefore be important in ascribing a value and deciding whether to engage in goal-directed social behaviours. 
These lines of evidence point to there being regions that are specialised for different components of social cognition. In certain circumstances the response in these regions is greater to more sophisticated ToM processing, to greater magnitudes of others' rewards and pain, and when exerting more effort into prosocial behaviours. The response of these regions varies with trait levels of empathy, with greater responses in those who typically empathise more. Greater responses in these areas might reflect more effort being exerted, although such inferences are hard to make from neuroimaging data alone as changes in BOLD signal can occur for several reasons. However, what it more clear is that activity in these regions is linked to specialised social information processing, may be under the influence and carry information about the costs that empathic, ToM or prosocial processes may incur.

\subsection{Integrating social effort costs into circuits that motivate behaviours}

How does this socially specific information get integrated in order to motivate social acts? Regions that have been linked to effort-based decision-making, such as parts of the DLPFC, AI and the dACC are strongly anatomically connected to regions linked to ToM, altruism and empathy. The dACC, AI and DLPFC receive monosynaptic input from the ACCg, and several portions of the MPFC (Vogt, 2009). Moreover, the DLPFC and AI have strong connections to the TPJ and sgACC (Dal Monte et al., 2020; Moll et al., 2005; Petrides and Pandya, 2007, 2006, 1999; Seltzer and Pandya, 1978; Vogt, 2009). Each of the systems in the brain that shows some specialisation for social information processing, is therefore connected to a system that plays an important role in deciding whether to exert effort for reward in non-social situations. This makes the core-circuit ideally placed to integrate and learn how costly many different facets of social cognition are, in the same manner that this circuit learns to the costs and benefits of other non-social effortful processes. Thus, our central claim is that these regions will signal the value of exerting effort into social processes, in the same manner as they signal the value of engaging in other tasks. At this stage, more work is required to directly test these claims, but this framework outlines the potential for understanding social cognition and behaviour by examining how the effort of social information is processed, ascribed value and influences social behaviour.

\section{Impaired motivation underlying psychiatric traits}

As highlighted above, motivation does not just impact performance in tasks, but a number of motivationally relevant traits that modulate everyday social behaviour. Apathy - a reduction in goal-directed behaviour - and anhedonia - a reduction in pleasure from rewarding activities - are highly common symptoms across neurological and psychiatric disorders (Husain and Roiser, 2018; Le Heron et al., 2017). They are also present, in milder forms, in the healthy population and come at a significant societal cost (Ang et al., 2017; Bonnelle et al., 2014; Van Reekum et al., 2005).

Anhedonia has long been linked to a reduced sensitivity to rewards (Husain and Roiser, 2018). In contrast theories suggest that that a key feature of apathy is a heightened sensitivity to effort (Ang et al., 2017). Apathetic people - as well as patients with severe levels of apathy show a reduced willingness to choose to exert physical effort for rewards compared to non-apathetic people (Ang et al., 2017; Bonnelle et al., 2014; Chong et al., 2015; Hartmann et al., 2015; Le Heron et al., 2017; Lockwood et al., 2017a; 2017b; Pessiglione et al., 2018). While a significant amount of evidence links apathy to increased effort sensitivity and reduced motivation (Husain and Roiser, 2018; Le Heron et al., 2017) little work has discussed the extent to which this applied to social cognition and behaviour.

Why would this affect social behaviour? Both apathy and anhedonia have been characterised as multidimensional constructs. In both healthy people, and in neurological disorders, both putatively have a social dimension (Ang et al., 2017, 2018). These dimensions are partially independent from other components of the non-social aspects of apathy and anhedonia, so an individual can be highly socially motivated - but not behaviourally - and vice versa. Each of these different dimensions may have consequences for social information processing. Importantly this suggests that even healthy people who have the capacity to perform social behaviours may suffer a sub-clinical, trait reduction in the willingness to engage in them (Lockwood et al., 2017a; 2017b).

\subsection{Social motivation phenotypes}

Motivation to exert effort can differ between different types of task. For instance, although similar underlying neural mechanisms process cognitive and physical effort based decisions, behaviourally people show a preference for exerting one type of effort over the other (Chong et al., 2017). The same may be true for different types of social process. That is, people may find the cognitive costs of empathising very effortful and avoid it, but may find ToM processes less costly and require less exertion. Indeed, there has been debate for decades about the degree to which different social processes are specialised behaviorally, cognitively and neurally, from each other, and from other non-social domain-general processes such as working memory (Lockwood et al., 2020b). Future research will therefore need to measure the motivation to exert effort into different types of social task, to assess the degree to which distinct social processes are orthogonal in terms of their effort cost.

Effort-based decision-making paradigms are also fruitful for understanding which impairments and individual differences are linked to what aspects of social behaviour. As they typically manipulate reward and effort independently, it is possible to examine whether people may show a reduction in the willingness to perform a social task, because they are not capable, willing to exert the effort or incentivised by the reward. A considerable amount of evidence showing individual differences in reward sensitivity suggests that similar differences in effort sensitivities might exist too. Thus, it may be possible to use effort-based tasks to identify phenotypes of social motivation and begin to explain the different cognitive processes that lead to people becoming socially withdrawn or antisocial.

Some examples of this approach have already been undertaken. In the study by Lockwood and colleagues (Lockwood et al., 2017a; 2017b) outlined above, they found that the social dimension of apathy was linked to a reduced willingness to put in effort specifically for another person, and not linked to their motivation to benefit themselves. More recent work using the same task (Lockwood et al., 2020) extended these findings showing that older adults are more willing to exert force for others, compared to younger adults, suggesting older adults are more prosocial. This highlights the utility of measuring effort discounting behaviour in different populations.

However, psychopathic traits varied with the difference between their willingness to put in effort for others relative to self. So, different traits mapped onto to different patterns of effort discounting behaviour when deciding whether to be altruistic. Another study provided evidence showing that individuals with Autism Spectrum Disorders (ASD) are in fact more willing to put in higher efforts to benefit another person for low rewards, but have typical levels of motivation to benefit themselves (Mosner et al., 2017, Fig. 2D) whereas people with impairments in affective processing which are often linked to the presence of psychopathic traits show reduced levels of motivation to exert effort for another person (Contreras-Huerta et al., 2020). Psychopathy is also often associated with motivational dysfunctions (Murray et al., 2018), including apathy, and recent attempts have aimed to tease apart what aspect of motivation, social or otherwise, is reduced (Hare and Neumann, 2008; Lockwood et al., 2017a, 2017b; Meffert et al., 2013; Viding and McCrory, 2019). This work may benefit from examining effort-based decisions in different contexts. Thus, apathy, psychopathy 
and ASD may have distinct social motivation phenotypes when it comes to prosocial behaviour, which are only teased apart by measuring effort and reward sensitivity for self and other.

Recent evidence suggests that people who are apathetic may be less empathetic. Lockwood and colleagues correlated self-reported levels of empathy, with the different dimensions of apathy (Lockwood et al., 2017a; 2017b). They found that affective empathy was strongly correlated with the emotional dimension of apathy, with a factor analysis revealing that both of these traits loaded on the same factor together. Although it does not provide direct evidence that emotionally apathetic people avoid empathising because it is effortful, it supports the claim that empathy may be partially driven by motivation and not capacity alone.

The same could potentially extend to other social processes such as ToM. Indeed, self-reported cognitive empathy - a component of ToM correlates with behavioural and social apathy, suggesting that people who have reduced motivation may show a reduced tendency to engage in ToM processes (Lockwood et al., 2017a;, 2017b). Moreover, individuals with ASD and schizophrenia both show reduced ToM task performance (Baron-Cohen et al., 1985; Chevallier et al., 2012). However, while the former has a capacity deficit, there is evidence that individuals with the latter show reduced motivation that could impair ToM (Addington et al., 2006; Baranek, 1999; Baron-Cohen et al., 2001; Dawson et al., 2004; Frith, 2004; White et al., 2009). Indeed, levels of apathy are high amongst schizophrenia patients, and they also show a greater aversion to exerting effort (Fulford et al., 2018; HartmannRiemer et al., 2018). This suggests that pathological deficits in social cognition may depend on peoples' aversion to cognitive effort and that different motivation phenotypes might explain differences in ToM performance in healthy people.

Although work in this field is very much in its infancy, these findings outline the potential for disentangling capacity changes from motivational ones when studying aberrant social behaviours. Different disorders of social cognition may relate to different aspects of effort and reward, apathy and anhedonia. Only by using tasks that disentangle the effort of a social process, from the incentives to undertake it, will we able to characterise social motivation phenotypes in healthy in clinical disorders.

\section{Concluding remarks}

Much of our behaviour is goal-directed. Here, we have outlined how many social behaviours and socio-cognitive processes are also goal-directed, require effortful exertion, and due to the subjective nature of effort, people vary considerably in their motivation to overcome the costs of exertion. Thus, whilst some social processes engage partially specialised circuits, they also elicit responses in a domain-general system that guides effort-based decision-making for social and non-social behaviours alike. We suggest that variability in these mechanisms is linked to apathy - a trait aversion to goal-directed behaviour- which may prove a powerful modulator of social cognition and behaviour. Therefore, understanding healthy and impaired social cognition will depend on probing its effortful, goal-directed nature.

\section{Acknowledgements}

This work was funded by a BBSRC David Phillips Fellowship (BB/ R010668/1) to M.A.J.A.; and a Becas Chile-CONICYT program to L.S.C.H.

\section{References}

Addington, J., Saeedi, H., Addington, D., 2006. Influence of social perception and social knowledge on cognitive and social functioning in early psychosis. Br. J. Psychiatry. https://doi.org/10.1192/bjp.bp.105.021022.

Amodio, D.M., Frith, C.D., 2006. Meeting of minds: the medial frontal cortex and social cognition. Nat. Rev. Neurosci. https://doi.org/10.1038/nrn1884atthew A. J.

Andreoni, J., Rao, J.M., Trachtman, H., 2017. Avoiding the ask: a field experiment on altruism, empathy, and charitable giving. J. Polit. Econ. 125, 625-653. https://doi. org/10.1086/691703.

Ang, Y.-S., Lockwood, P., Apps, M.A.J., Muhammed, K., Husain, M., 2017. Distinct subtypes of apathy revealed by the apathy motivation index. PLoS One 12. https://doi. org/10.1371/journal.pone.0169938.

Ang, Y.S., Lockwood, P.L., Kienast, A., Plant, O., Drew, D., Slavkova, E., Tamm, M., Husain, M., 2018. Differential impact of behavioral, social, and emotional apathy on Parkinson's disease. Ann. Clin. Transl. Neurol. https://doi.org/10.1002/acn3.626.

Apperly, I.A., Butterfill, S.A., 2009. Do humans have two systems to track beliefs and Belief-Like States? Psychol. Rev. https://doi.org/10.1037/a0016923.

Apperly, I.A., Riggs, K.J., Simpson, A., Chiavarino, C., Samson, D., 2006. Is belief reasoning automatic? Psychol. Sci. https://doi.org/10.1111/j.1467-9280.2006.01791.x.

Apperly, I.A., Samson, D., Humphreys, G.W., 2009. Studies of Adults Can Inform Accounts of Theory of Mind Development. Dev. Psychol. https://doi.org/10.1037/a0014098.

Apps, M.A.J., Ramnani, N., 2014. The anterior cingulate gyrus signals the net value of others' rewards. J. Neurosci. 34. https://doi.org/10.1523/JNEUROSCI.2701-13. 2014.

Apps, M.A.J., Green, R., Ramnani, N., 2013. Reinforcement learning signals in the anterior cingulate cortex code for others' false beliefs. Neuroimage 64. https://doi. org/10.1016/j.neuroimage.2012.09.010.

Apps, M.A.J., Grima, L.L., Manohar, S., Husain, M., 2015a. The role of cognitive effort in subjective reward devaluation and risky decision-making. Sci. Rep. 5. https://doi. org/10.1038/srep16880.

Apps, M.A.J., Lesage, E., Ramnani, N., 2015b. Vicarious reinforcement learning signáis when instructing others. J. Neurosci. 35. https://doi.org/10.1523/JNEUROSCI.366914.2015.

Apps, M.A.J., Rushworth, M.F.S., Chang, S.W.C., 2016. The anterior cingulate gyrus and social cognition: tracking the motivation of others. Neuron 90. https://doi.org/10. 1016/j.neuron.2016.04.018.

Balsters, J.H., Apps, M.A., Bolis, D., Lehner, R., Gallagher, L., Wenderoth, N., 2017. Disrupted prediction errors index social deficits in autism spectrum disorder. Brain 140. https://doi.org/10.1093/brain/aww287.

Baranek, G.T., 1999. Autism during infancy: a retrospective video analysis of sensorymotor and social behaviors at 9-12 months of age. J. Autism Dev. Disord. https://doi. org/10.1023/A:1023080005650.

Baron-Cohen, S., Leslie, A.M., Frith, U., 1985. Does the autistic child have a "theory of mind"? Cognition. https://doi.org/10.1016/00100277(85)90022-8.

Baron-Cohen, S., Wheelwright, S., Hill, J., Raste, Y., Plumb, I., 2001. The "reading the Mind in the Eyes" Test revised version: a study with normal adults, and adults with Asperger syndrome or high-functioning autism. J. Child Psychol. Psychiatry Allied Discip. https://doi.org/10.1017/S0021963001006643.

Berg, J., Dickhaut, J., McCabe, K., 1995. Trust, reciprocity, and social history. Games Econ. Behav. https://doi.org/10.1006/game.1995.1027.

Blair, R.J.R., 2018. Traits of empathy and anger: implications for psychopathy and other disorders associated with aggression. Philos. Trans. R. Soc. B Biol. Sci. 373. https:// doi.org/10.1098/rstb. 2017.0155.

Bonnelle, V., Veromann, K.-R., Heyes, S.B., Sterzo, E., Lo, Manohar, S., Husain, M., 2014. Characterization of reward and effort mechanisms in apathy. J. Physiol. (Paris). https://doi.org/10.1016/j.jphysparis.2014.04.002.

Bonnelle, V., Manohar, S., Behrens, T., Husain, M., 2016. Individual differences in premotor brain systems underlie behavioral apathy. Cereb. Cortex 26, 807-819. https:// doi.org/10.1093/cercor/bhv247.

Bortolini, T., Bado, P., Hoefle, S., Engel, A., Zahn, R., De Oliveira Souza, R., Dreher, J.C., Moll, J., 2017. Neural bases of ingroup altruistic motivation in soccer fans. Sci. Rep. https://doi.org/10.1038/s41598-017-15385-7.

Camerer, C.F., Ho, T.H., Chong, J.K., 2004. A cognitive hierarchy model of games. Q. J. Econ. https://doi.org/10.1162/0033553041502225.

Cameron, C.D., Payne, B.K., 2011. Escaping affect: how motivated emotion regulation creates insensitivity to mass suffering. J. Pers. Soc. Psychol. 100, 1-15. https://doi. org $/ 10.1037 / \mathrm{a} 0021643$.

Cameron, C.D., Spring, V.L., Todd, A.R., 2017. The empathy impulse: a multinomial model of intentional and unintentional empathy for pain. Emotion. https://doi.org/ 10.1037/emo0000266.

Cameron, C.D., Harris, L.T., Payne, B.K., 2016. The emotional cost of humanity: anticipated exhaustion motivates dehumanization of stigmatized targets. Soc. Psychol. Personal. Sci. 7, 105-112. https://doi.org/10.1177/1948550615604453.

Cameron, C.D., Hutcherson, C.A., Ferguson, A.M., Scheffer, J.A., Inzlicht, M., 2019. Empathy is hard work: people choose to avoid empathy because of its cognitive costs. J. Exp. Psychol.: General 148, 962-976.

Cao, Y., Contreras-Huerta, L.S., McFadyen, J., Cunnington, R., 2015. Racial bias in neural response to others' pain is reduced with other-race contact. Cortex 70, 68-78.

Carrillo, M., Han, Y., Migliorati, F., Liu, M., Gazzola, V., Keysers, C., 2019. Emotional mirror neurons in the rat's anterior cingulate cortex. Curr. Biol. 29, 1301-1312.

Chang, S.W.C., Gariepy, J.-F., Platt, M.L., 2013. Neuronal reference frames for social decisions in primate frontal cortex. Nat. Neurosci. 16, 243-250. https://doi.org/10. 1038/nn.3287.

Chevallier, C., Kohls, G., Troiani, V., Brodkin, E.S., Schultz, R.T., 2012. The social motivation theory of autism. Trends Cogn. Sci. 16, 231-239. https://doi.org/10.1016/j. tics.2012.02.007.

Chong, T.T.-J., Bonnelle, V., Manohar, S., Veromann, K.-R., Muhammed, K., Tofaris, G.K., Hu, M., Husain, M., 2015. Dopamine enhances willingness to exert effort for reward in Parkinson's disease. Cortex. https://doi.org/10.1016/j.cortex.2015.04.003.

Chong, J.K., Ho, T.H., Camerer, C., 2016. A generalized cognitive hierarchy model of games. Games Econ. Behav. https://doi.org/10.1016/j.geb.2016.08.007. 
Chong, T.T.J., Apps, M., Giehl, K., Sillence, A., Grima, L.L., Husain, M., 2017. Neurocomputational mechanisms underlying subjective valuation of effort costs. PLoS Biol. 15. https://doi.org/10.1371/journal.pbio.1002598.

Cikara, M., Bruneau, E.G., Saxe, R.R., 2011. Us and them: intergroup failures of empathy. Curr. Dir. Psychol. Sci. https://doi.org/10.1177/0963721411408713.

Contreras-Huerta, L.S., Baker, K.S., Reynolds, K.J., Batalha, L., Cunnington, R., 2013. Racial bias in neural empathic responses to pain. PLoS One 8. https://doi.org/10. 1371/journal.pone.0084001.

Contreras-Huerta, L.S., Lockwood, P.L., Bird, G., Apps, M.A.J., Crockett, M.J., In press. Prosocial behaviour is associated with transdiagnostic markers of affective sensitivity in multiple domains. Emotion. doi: 10.1037/emo0000813

Conway, J.R., Catmur, C., Bird, G., 2019. Understanding individual differences in theory of mind via representation of minds, not mental states. Psychon. Bull. Rev. https:/ doi.org/10.3758/s13423-018-1559-x.

Coricelli, G., Nagel, R., 2009. Neural correlates of depth of strategic reasoning in medial prefrontal cortex. Proc. Natl. Acad. Sci. U. S. A. https://doi.org/10.1073/pnas. 0807721106.

Critchfield, T.S., Kollins, S.H., 2001. Temporal discounting: basic research and the analysis of socially important behavior. J. Appl. Behav. Anal. 34, 101-122. https://doi. org/10.1901/jaba.2001.34-101.

Crockett, M.J., Kurth-Nelson, Z., Siegel, J.Z., Dayan, P., Dolan, R.J., 2014. Harm to others outweighs harm to self in moral decision making. Proc. Natl. Acad. Sci. 111https:// doi.org/10.1073/pnas.1424572112. 173201-17325.

Croxson, P.L., Walton, M.E., O’Reilly, J.X., Behrens, T.E.J., Rushworth, M.F.S., 2009. Effort-based cost-benefit valuation and the human brain. J. Neurosci. 29, 4531-4541.

Cutler, J., Campbell-Meiklejohn, D., 2019. A comparative fMRI meta-analysis of altruistic and strategic decisions to give. Neuroimage 184, 227-241. https://doi.org/10.1016/ j.neuroimage.2018.09.009.

Davis, M.H., Conklin, L., Smith, A., Luce, C., 1996. Effect of perspective taking on the cognitive representation of persons: a merging of self and other. J. Pers. Soc. Psychol. https://doi.org/10.1037/0022-3514.70.4.713.

Dawson, G., Toth, K., Abbott, R., Osterling, J., Munson, J., Estes, A., Liaw, J., 2004. Early social attention impairments in autism: social orienting, joint attention, and attention to distress. Dev. Psychol. https://doi.org/10.1037/0012-1649.40.2.271.

de Greck, M., Wang, G., Yang, X., Wang, X., Northoff, G., Han, S., 2012d. Neural substrates underlying intentional empathy. Soc. Cogn. Affect. Neurosci. 7, 135-144. https://doi.org/10.1093/scan/nsq093.

de Vignemont, F., Singer, T., 2006d. The empathic brain: how, when and why? Trends Cogn. Sci. 10, 435-441. https://doi.org/10.1016/j.tics.2006.08.008.

de Waal, F.B.M., 2008d. Putting the altruism back into altruism: the evolution of empathy. Annu. Rev. Psychol. 59, 279-300. https://doi.org/10.1146/annurev.psych.59. 103006.093625.

Decety, J., 2015. The neural pathways, development and functions of empathy. Curr. Opin. Behav. Sci. https://doi.org/10.1016/j.cobeha.2014.12.001.

Devaine, M., Hollard, G., Daunizeau, J., 2014. Theory of mind: Did evolution fool us? PLoS One. https://doi.org/10.1371/journal.pone.0087619.

Devaine, M., San-Galli, A., Trapanese, C., Bardino, G., Hano, C., Saint Jalme, M., Bouret, S., Masi, S., Daunizeau, J., 2017. Reading wild minds: a computational assay of Theory of Mind sophistication across seven primate species. PLoS Comput. Biol. https://doi.org/10.1371/journal.pcbi.1005833.

Dickinson, A., 1985. Actions and habits : the development of behavioural autonom y. Philos. Trans. R. Soc. London. B, Biol. Sci. 308, 67-78.

DiMenichi, B.C., Tricomi, E., 2017. Increases in brain activity during social competition predict decreases in working memory performance and later recall. Hum. Brain Mapp. https://doi.org/10.1002/hbm. 23396.

Döhnel, K., Schuwerk, T., Meinhardt, J., Sodian, B., Hajak, G., Sommer, M., 2012. Functional activity of the right temporo-parietal junction and of the medial prefrontal cortex associated with true and false belief reasoning. Neuroimage. https://doi.org/ 10.1016/j.neuroimage.2012.01.073.

Dolan, R.J., Dayan, P., 2013. Goals and habits in the brain. Neuron 80, 312-325. https:// doi.org/10.1016/j.neuron.2013.09.007.

Dubey, I., Ropar, D., Hamilton, A., 2018. Comparison of choose-a-movie and approach-avoidance paradigms to measure social motivation. Motiv. Emot. 42, 190-199.

Engen, H.G., Singer, T., 2013. Empathy circuits. Curr. Opin. Neurobiol. 23, 275-282. https://doi.org/10.1016/j.conb.2012.11.003.

Epley, N., Keysar, B., Van Boven, L., Gilovich, T., 2004. Perspective taking as egocentric anchoring and adjustment. J. Pers. Soc. Psychol. https://doi.org/10.1037/0022 3514.87.3.327.

Esposito, F, Rochat, L., der Linden, A.-C., Lekeu, F. Charnallet, A., der Linden, M., 2014 Apathy in aging: are lack of interest and lack of initiative dissociable? Arch. Gerontol Geriatr. 58, 43-50.

Fehr, E., Camerer, C.F., 2007. Social neuroeconomics: the neural circuitry of social preferences. Trends Cogn. Sci. 11, 419-427. https://doi.org/10.1016/j.tics.2007.09. 002.

Fehr, E., Fischbacher, U., 2003. The nature of human altruism. Nature 425, 785-791. https://doi.org/10.1038/nature02043.

Forsythe, R., Horowitz, J.L., Savin, N.E., Sefton, M., 1994. Fairness in simple bargaining experiments. Games Econ. Behav. https://doi.org/10.1006/game.1994.1021.

Frith, C.D., 2004. Schizophrenia and theory of mind. Psychol. Med. https://doi.org/10 1017/s0033291703001326.

Frith, C.D., Frith, U., 1999. Cognitive psychology - interacting minds - A biological basis. Science 286 (80), 1692-1695.

Frith, C.D., Frith, U., 2008. Implicit and explicit processes in social cognition. Neuron. https://doi.org/10.1016/j.neuron.2008.10.032.

Frith, U., Frith, C., 2010. The social brain: allowing humans to boldly go where no other species has been. Philos. Trans. R. Soc. B-Biological Sci. 365, 165-175. https://doi. org $/ 10.1098 /$ rstb.2009.0160.

Fulford, D., Treadway, M., Woolley, J., 2018. Social motivation in schizophrenia: the impact of oxytocin on vigor in the context of social and nonsocial reinforcement. J. Abnorm. Psychol. https://doi.org/10.1037/abn0000320.

Gläscher, J., Daw, N., Dayan, P., O’Doherty, J.P., 2010. States versus rewards: dissociable neural prediction error signals underlying model-based and model-free reinforcement learning. Neuron 66, 585-595. https://doi.org/10.1016/j.neuron.2010.04.016.

Gleichgerrcht, E., Decety, J., 2013. Empathy in clinical practice: how individual dispositions, gender, and experience moderate empathic concern, burnout, and emotional distress in physicians. PLoS One 8, 1-12. https://doi.org/10.1371/journal. pone.0061526.

Guth, W., Schmittberger, R., Schwarze, B., 1983. An experimental analysis of ultimatum bargaining. J. Econ. Behav. Organ. 3, 367-388.

Gutsell, J.N., Inzlicht, M., 2012. Intergroup differences in the sharing of emotive states: neural evidence of an empathy gap. Soc. Cogn. Affect. Neurosci. https://doi.org/10 1093/scan/nsr035.

Hamilton, A.Fd.C., 2009. Goals, intentions and mental states: challenges for theories of autism. J. Child Psychol. Psychiatry. https://doi.org/10.1111/j.1469-7610.2009. 02098.x.

Hampton, A.N., Bossaerts, P., O'Doherty, J.P., 2008. Neural correlates of mentalizingrelated computations during strategic interactions in humans. Proc. Natl. Acad. Sci. U. S. A. 105, 6741-6746. https://doi.org/10.1073/pnas.0711099105.

Hansen, E.M., Eklund, J.H., Hallén, A., Bjurhager, C.S., Norrström, E., Viman, A., Stocks, E.L., 2018. Does Feeling Empathy Lead to Compassion Fatigue or Compassion Satisfaction? The Role of Time Perspective. J. Psychol. 152, 630-645. https://doi org/10.1080/00223980.2018.1495170.

Hare, R.D., Neumann, C.S., 2008. Psychopathy as a clinical and empirical construct. Annu. Rev. Clin. Psychol. 4, 217-246. https://doi.org/10.1146/annurev.clinpsy.3. 022806.091452.

Hartmann, M.N., Hager, O.M., Reimann, A.V., Chumbley, J.R., Kirschner, M., Seifritz, E., Tobler, P.N., Kaiser, S., 2015. Apathy but not diminished expression in schizophrenia is associated with discounting of monetary rewards by physical effort. Schizophr. Bull. 41, 503-512. https://doi.org/10.1093/schbul/sbu102.

Hartmann-Riemer, M., Kirschner, M., Kaiser, S., 2018. Effort-based decision-making paradigms as objective measures of apathy in schizophrenia? Curr. Opin. Behav. Sci. https://doi.org/10.1016/j.cobeha.2018.01.009.

Hein, G., Silani, G., Preuschoff, K., Batson, C.D., Singer, T., 2010. Neural responses to Ingroup and outgroup members' suffering predict individual differences in costly helping. Neuron 68, 149-160. https://doi.org/10.1016/j.neuron.2010.09.003.

Husain, M., Roiser, J.P., 2018. Neuroscience of apathy and anhedonia: a transdiagnostic approach. Nat. Rev. Neurosci. 1.

Iacoboni, M., 2008. Imitation, empathy, and mirror neurons. Annu. Rev. Psychol. https:// doi.org/10.1146/annurev.psych.60.110707.163604

Imas, A., 2014. Working for the warm glow: on the benefits and limits of prosocial incentives. J. Public Econ. https://doi.org/10.1016/j.jpubeco.2013.11.006.

Inzlicht, M., Shenhav, A., Olivola, C.Y., 2018. The effort paradox: effort is both costly and valued. Trends Cogn. Sci. https://doi.org/10.1016/j.tics.2018.01.007.

Kahneman, D., 2011. Thinking, Fast and Slow. Farrar, Straus and Giroux. New York, NY.

Kahneman, D., Knetsch, J., Thaler, R., 1986. Fairness and the assumptions of economics. J. Bus. 59.

Kennerley, S.W., Wallis, J.D., 2009a. Evaluating choices by single neurons in the frontal lobe: outcome value encoded across multiple decision variables. Eur. J. Neurosci. 29, 2061-2073. https://doi.org/10.1111/j.1460-9568.2009.06743.x.

Keysers, C., Gazzola, V., 2007. Integrating simulation and theory of mind: from self to social cognition. Trends Cogn. Sci. https://doi.org/10.1016/j.tics.2007.02.002.

Kitcher, P., 1993. The evolution of human altruism. J. Philos. 90, 497-516.

Klein-Flügge, M.C., Kennerley, S.W., Friston, K., Bestmann, S., 2016. Neural signatures of value comparison in human cingulate cortex during decisions requiring an effortreward trade-off. J. Neurosci. https://doi.org/10.1523/jneurosci.0292-16.2016.

Klimecki, O., Singer, T., 2012. Empathic distress fatigue rather than compassion fatigue? Integrating findings from empathy research in psychology and social neuroscience. Pathol. altruism 368-383.

Kool, W., Botvinick, M., 2018. Mental labour. Nat. Hum. Behav. https://doi.org/10.1038/ s41562-018-0401-9.

Korucu, I., Selcuk, B., Harma, M., 2017. Self-regulation: relations with theory of mind and social behaviour. Infant Child Dev. https://doi.org/10.1002/icd.1988.

Kovács, Á.M., Téglás, E., Endress, A.D., 2010. The social sense: susceptibility to others' beliefs in human infants and adults. Science(80). https://doi.org/10.1126/science. 1190792.

Kurniawan, I.T., Guitart-Masip, M., Dayan, P., Dolan, R.J., 2013. Effort and \{Valuation\} in the brain: the effects of anticipation and execution. J. Neurosci. 33, 6160-6169. https://doi.org/10.1523/jneurosci.4777-12.2013.

Kurzban, R., Duckworth, A., Kable, J.W., Myers, J., 2013. An opportunity cost model of subjective effort and task performance. Behav. Brain Sci. 36, 661-679. https://doi. org/10.1017/S0140525X12003196.

Le Bouc, R., Pessiglione, M., 2013. Imaging social motivation: distinct brain mechanisms drive effort production during collaboration versus competition. J. Neurosci. https:// doi.org/10.1523/jneurosci.0143-13.2013.

Le Heron, C., Apps, M.A.J., Husain, M., 2017. The anatomy of apathy: a neurocognitive framework for amotivated behavior. Neuropsychologia. https://doi.org/10.1016/j neuropsychologia.2017.07.003.

Le Heron, C., Plant, O., Manohar, S., Ang, Y.S., Jackson, M., Lennox, G., Hu, M.T., Husain, M., 2018. Distinct effects of apathy and dopamine on effort-based decision-making in Parkinson's disease. Brain 141, 1455-1469. https://doi.org/10.1093/brain/awy110.

Lee, D., Seo, H., 2016. Neural basis of strategic decision making. Trends Neurosci. https:// 
doi.org/10.1016/j.tins.2015.11.002.

Lin, S., Keysar, B., Epley, N., 2010. Reflexively mindblind: using theory of mind to interpret behavior requires effortful attention. J. Exp. Soc. Psychol. https://doi.org/10. 1016/j.jesp.2009.12.019.

Lockwood, P.L., 2016. The anatomy of empathy: Vicarious experience and disorders of social cognition. Behav. Brain Res. 311, 255-266. https://doi.org/10.1016/j.bbr. 2016.05.048.

Lockwood, P.L., Sebastian, C.L., McCrory, E.J., Hyde, Z.H., Gu, X., De Brito, S.A., Viding, E., 2013. Association of callous traits with reduced neural response to others' pain in children with conduct problems. Curr. Biol. https://doi.org/10.1016/j.cub.2013.04. 018.

Lockwood, P.L., Apps, M.A.J., Roiser, J.P., Viding, E., 2015. Encoding of vicarious reward prediction in anterior cingulate cortex and relationship with trait empathy. J. Neurosci. https://doi.org/10.1523/jneurosci.1703-15.2015.

Lockwood, P.L., Apps, M.A.J., Valton, V., Viding, E., Roiser, J.P., 2016. Neurocomputational mechanisms of prosocial learning and links to empathy. Proc. Natl. Acad. Sci. https://doi.org/10.1073/PNAS.1603198113.

Lockwood, P.L., Abdurahman, A., Gabay, A.S., Drew, D., Tamm, M., Husain, M., Apps, M.A.J., 2020. Ageing increases prosocial motivation for effort. PsyArXiv. https://doi. org/10.31234/osf.io/8c5ra.

Lockwood, Patricia L., Ang, Y.S., Husain, M., Crockett, M.J., 2017a. Individual differences in empathy are associated with apathy-motivation. Sci. Rep. https://doi.org/10. 1038/s41598-017-17415-w.

Lockwood, Patricia L., Hamonet, M., Zhang, S.H., Ratnavel, A., Salmony, F.U., Husain, M. Apps, M.A.J., 2017b. Prosocial apathy for helping others when effort is required. Nat Hum. Behav. 1 s41562-017-0131.

Lockwood, P.L., Wittmann, M.K., Apps, M.A.J., Klein-Flügge, M.C., Crockett, M.J. Humphreys, G.W., Rushworth, M.F.S., 2018. Neural mechanisms for learning self and other ownership. Nat. Commun. 9, 1-11.

Lockwood, P.L., Apps, M.A.J., Chang, S.W.C., In press. Is there a "social" brain? Implementations and algorithms. Trends Cogn. Sci.

Mahy, C.E.V., Moses, L.J., Pfeifer, J.H., 2014. How and where: theory-of-mind in the brain. Dev. Cogn. Neurosci. https://doi.org/10.1016/j.dcn.2014.01.002.

Manohar, S.G., Chong, T.T.J., Apps, M.A.J., Batla, A., Stamelou, M., Jarman, P.R., Bhatia, K.P., Husain, M., 2015. Reward pays the cost of noise reduction in motor and cognitive control. Curr. Biol. 25, 1707-1716. https://doi.org/10.1016/j.cub.2015.05. 038.

Marcora, S., 2009. Perception of effort during exercise is independent of afferent feedback from skeletal muscles, heart, and lungs. J. Appl. Physiol. 106, 2060-2062. https:// doi.org/10.1152/japplphysiol.00367.2009.

Massar, S.A.A., Csathó, Á., Van der Linden, D., 2018. Quantifying the motivational effects of cognitive fatigue through effort-based decision making. Front. Psychol. 9, 1-5. https://doi.org/10.3389/fpsyg.2018.00843.

Meffert, H., Gazzola, V., Den Boer, J.A., Bartels, A.A.J., Keysers, C., 2013. Reduced spontaneous but relatively normal deliberate vicarious representations in psychopathy. Brain 136, 2550-2562.

Meinhardt-Injac, B., Daum, M.M., Meinhardt, G., Persike, M., 2018. The two-systems account of theory of mind: testing the links to social-perceptual and cognitive abilities. Front. Hum. Neurosci. https://doi.org/10.3389/fnhum.2018.00025.

Meyer, M.L., Spunt, R.P., Berkman, E.T., Taylor, S.E., Lieberman, M.D., 2012. Evidence for social working memory from a parametric functional MRI study. Proc. Natl. Acad. Sci. 109, 1883-1888.

Meyniel, F., Sergent, C., Rigoux, L., Daunizeau, J., Pessiglione, M., 2013. Neurocomputational account of how the human brain decides when to have a break. Proc. Natl. Acad. Sci. U. S. A. 110, 2641-2646.

Moll, Jorge, Zahn, R., De Oliveira-Souza, R., Krueger, F., Grafman, J., 2005. Opinion: the neural basis of human moral cognition. Nat. Rev. Neurosci. https://doi.org/10.1038/ nrn1768.

Moll, J., De Oliveira-Souza, R., Zahn, R., 2008. The neural basis of moral cognition: sentiments, concepts, and values. Ann. N. Y. Acad. Sci. https://doi.org/10.1196/ annals.1440.005.

Monte, Dal, O, Chu, C.C.J, Fagan, N.A, Chang, S.W.C, 2020. Specialized medial prefrontal-amygdala coordination in other-regarding decision preference. Nat. Neurosci. $1-10$.

Morelli, S.A., Sacchet, M.D., Zaki, J., 2015. Common and distinct neural correlates of personal and vicarious reward: a quantitative meta-analysis. Neuroimage 112 244-253. https://doi.org/10.1016/j.neuroimage.2014.12.056.

Mosner, M.G., Kinard, J.L., McWeeny, S., Shah, J.S., Markiewitz, N.D., DamianoGoodwin, C.R., Burchinal, M.R., Rutherford, H.J.V., Greene, R.K., Treadway, M.T., Dichter, G.S., 2017. Vicarious effort-based decision-making in autism Spectrum disorders. J. Autism Dev. Disord. 47, 2992-3006. https://doi.org/10.1007/s10803-017 3220-3.

Müller, T., Apps, M.A.J., 2018. Motivational fatigue: a neurocognitive framework for the impact of effortful exertion on subsequent motivation. Neuropsychologia. https:// doi.org/10.1016/j.neuropsychologia.2018.04.030.

Murray, L., Dotterer, H.L., Waller, R., Hyde, L.W., 2018. Neurogenetics approaches to understanding psychopathy. Routledge International Handbook of Psychopathy and Crime. Routledge, pp. 95-120.

Nash, J., 1950. The bargaining problem. Econometrica 18, 155-162.

Ochsner, K.N., Beer, J.S., Robertson, E.R., Cooper, J.C., Gabrieli, J.D.E., Kihsltrom, J.F. D'Esposito, M., 2005. The neural correlates of direct and reflected self-knowledge. Neuroimage. https://doi.org/10.1016/j.neuroimage.2005.06.069.

Olsson, A., Knapska, E., Lindström, B., 2020. The neural and computational systems of social learning. Nat. Rev. Neurosci. 21, 197-212. https://doi.org/10.1038/s41583020-0276-4.

Pessiglione, M., Vinckier, F., Bouret, S., Daunizeau, J., Le Bouc, R., 2018. Why not try harder? Computational approach to motivation deficits in neuro-psychiatric diseases. Brain. https://doi.org/10.1093/brain/awx278.

Petrides, M., Pandya, D.N., 1999. Dorsolateral prefrontal cortex: comparative cytoarchi tectonic analysis in the human and the macaque brain and corticocortical connection patterns. Eur. J. Neurosci. 11, 1011-1036.

Petrides, M., Pandya, D.N., 2006. Efferent association pathways originating in the cauda prefrontal cortex in the macaque monkey. J. Comp. Neurol. 498, 227-251. https:// doi.org/10.1002/cne.21048.

Petrides, M., Pandya, D.N., 2007. Efferent association pathways from the rostral prefrontal cortex in the macaque monkey. J. Neurosci. 27, 11573-11586. https://doi. org/10.1523/jneurosci.2419-07.2007.

Premack, D., Woodruff, G., 1978. Does the chimpanzee have a theory of mind? Behav. Brain Sci. https://doi.org/10.1017/S0140525X00076512.

Roberts, G., 1998. Competitive altruism: from reciprocity to the handicap principle. Proc. R. Soc. B Biol. Sci. 265, 427-431. https://doi.org/10.1098/rspb.1998.0312.

Roca, M., 2016. The relationship between executive functions and theory of mind: a long and winding road. J. Neurol. Neurosurg. Psychiatry. https://doi.org/10.1136/jnnp2015-312568.

Rothschild, B., 2006. Help for the Helper: the Psychophysiology of Compassion Fatigue and Vicarious Trauma. WW Norton Co.

Rudebeck, P.H., Buckley, M.J., Walton, M.E., Rushworth, M.F.S., 2006a. A role for the macaque anterior cingulate gyrus in social valuation. Science 313 (80), 1310-1312.

Rudebeck, P.H., Walton, M.E., Smyth, A.N., Bannerman, D.M., Rushworth, M.F.S., 2006b. Separate neural pathways process different decision costs. Nat. Neurosci. 9 , 1161-1168.

Ruff, C.C., Fehr, E., 2014. The neurobiology of rewards and values in social decision making. Nat. Rev. Neurosci. 15, 549-562. https://doi.org/10.1038/nrn3776.

Rushworth, M.F.S., Mars, R.B., Sallet, J., 2013. Are there specialized circuits for socia cognition and are they unique to humans? Curr. Opin. Neurobiol. 23, 436-442. https://doi.org/10.1016/j.conb.2012.11.013.

Salamone, J.D., Correa, M., 2018. Neurobiology and pharmacology of activational and effort-related aspects of motivation: rodent studies. Curr. Opin. Behav. Sci. 22, 114-120. https://doi.org/10.1016/j.cobeha.2018.01.026.

Samson, D., Apperly, I.A., Braithwaite, J.J., Andrews, B.J., Bodley Scott, S.E., 2010. Seeing it their Way: evidence for rapid and involuntary computation of what other people see. J. Exp. Psychol. Hum. Percept. Perform. https://doi.org/10.1037/ a0018729.

Saxe, R., 2010. The right temporo-parietal junction: a specific brain region for thinking about thoughts. in: Handbook of Theory of Mind.

Saxe, R., Powell, L.J., 2006. It's the thought that counts: specific brain regions for one component of theory of mind. Psychol. Sci. https://doi.org/10.1111/j.1467-9280. 2006.01768.x.

Schmidt, L., Lebreton, M., Cléry-Melin, M.L., Daunizeau, J., Pessiglione, M., 2012. Neural mechanisms underlying motivation of mental versus physical effort. PLoS Biol. 10, e1001266. https://doi.org/10.1371/journal.pbio.1001266.

Schumann, K., Zaki, J., Dweck, C.S., 2014. Addressing the empathy deficit: beliefs about the malleability of empathy predict effortful responses when empathy is challenging. J. Pers. Soc. Psychol. 107, 475-493. https://doi.org/10.1037/a0036738.

Seltzer, B., Pandya, D.N., 1978. Afferent cortical connections and architectonics of superior termporal sulcus and surrounding cortex in rhesus monkey. Brain Res. 149.

Shenhav, A., Botvinick, M.M., Cohen, J.D., 2013. The expected value of control: an integrative theory of anterior cingulate cortex function. Neuron 79, 217-240. https:// doi.org/10.1016/j.neuron.2013.07.007.

Shenhav, A., Musslick, S., Lieder, F., Kool, W., Griffiths, T.L., Cohen, J.D., Botvinick, M.M., 2017. Toward a rational and mechanistic account of mental effort. Annu. Rev. Neurosci. 40, 99-124. https://doi.org/10.1146/annurev-neuro-072116-031526.

Singer, T., Seymour, B., O’Doherty, J., Kaube, H., Dolan, R.J., Frith, C.D., 2004. Empathy for pain involves the affective but not sensory components of pain. Science 303 (80), $1157-1162$.

Sonnby-Borgström, M., 2002. Automatic mimicry reactions as related to differences in emotional empathy. Scand. J. Psychol. https://doi.org/10.1111/1467-9450.00312.

Stürmer, S., Snyder, M., Kropp, A., Siem, B., 2006. Empathy-motivated helping: the moderating role of group membership. Personal. Soc. Psychol. Bull. https://doi.org/ $10.1177 / 0146167206287363$

Surian, L., Caldi, S., Sperber, D., 2007. Attribution of beliefs by 13-month-old infants. Psychol. Sci. https://doi.org/10.1111/j.1467-9280.2007.01943.x.

Swart, H., Hewstone, M., Christ, O., Voci, A., 2011. Affective mediators of intergroup contact: a three-wave longitudinal study in South Africa. J. Pers. Soc. Psychol. 101 1221-1238. https://doi.org/10.1037/a0024450.

Van Reekum, R., Stuss, D.T., Ostrander, L., 2005. Apathy: why care? J. Neuropsychiatry clin. Neurosci. 17, 7-19. https://doi.org/10.1176/appi.neuropsych.17.1.7.

Varazzani, C., San-Galli, A., Gilardeau, S., Bouret, S., 2015. Noradrenaline and dopamine neurons in the reward/effort trade-off: a direct electrophysiological comparison in behaving monkeys. J. Neurosci. 35, 7866-7877. https://doi.org/10.1523/ JNEUROSCI.0454-15.2015.

Vassena, E., Silvetti, M., Boehler, C.N., Achten, E., Fias, W., Verguts, T., 2014. Overlapping neural systems represent cognitive effort and reward anticipation. PLoS One 9. https://doi.org/10.1371/journal.pone.0091008.

Viding, E., McCrory, E., 2019. Towards understanding atypical social affiliation in psychopathy. Lancet Psychiatry 6, 437-444. https://doi.org/10.1016/S2215-0366(19) 30049-5.

Viding, E., McCrory, E., Seara-Cardoso, A., 2014. Psychopathy. Curr. Biol. 24, R871-R874. https://doi.org/10.1016/j.cub.2014.06.055.

Vogt, B., 2009. Cingulate Neurobiology and Disease. Oxford University Press, New York.

Volz, L.J., Welborn, B.L., Gobel, M.S., Gazzaniga, M.S., Grafton, S.T., 2017. Harm to self outweighs benefit to others in moral decision making. Proc. Natl. Acad. Sci. 114, 
7963-7968. https://doi.org/10.1073/pnas.1706693114.

Vorauer, J.D., Martens, V., Sasaki, S.J., 2009. When trying to understand detracts from trying to behave: effects of perspective taking in intergroup interaction. J. Pers. Soc. Psychol. https://doi.org/10.1037/a0013411.

Walton, M.E., Kennerley, S.W., Bannerman, D.M., Phillips, P.E.M., Rushworth, M.F.S., 2006. Weighing up the benefits of work: $\{$ Behavioral $\}$ and neural analyses of effortrelated decision making. Neural Netw. 19, 1302-1314.

Westbrook, A., Kester, D., Braver, T.S., 2013. What is the subjective cost of cognitive effort? Load, trait, and aging effects revealed by economic preference. PLoS One 8 . https://doi.org/10.1371/journal.pone.0068210.

Westbrook, A., Lamichhane, B., Braver, T., 2019. The subjective value of cognitive effort is encoded by a domain-general valuation network. J. Neurosci. 39https://doi.org/ 10.1523/JNEUROSCI.3071-18.2019. 3934 LP - 3947.

White, S., Hill, E., Happé, F., Frith, U., 2009. Revisiting the strange stories: revealing mentalizing impairments in autism. Child Dev. https://doi.org/10.1111/j.1467 8624.2009.01319.x.

Wittmann, M.K., Lockwood, P.L., Rushworth, M.F.S., 2018. Neural mechanisms of social cognition in primates. Annu. Rev. Neurosci.

Yoshida, W., Dolan, R.J., Friston, K.J., 2008. Game theory of mind. PLoS Comput. Biol. https://doi.org/10.1371/journal.pcbi.1000254.

Zaki, J., 2014. Empathy: a motivated account. Psychol. Bull. 140, 1608.

Zaki, J., Cikara, M., 2015. Addressing empathic failures. Curr. Dir. Psychol. Sci. 24 471-476. https://doi.org/10.1177/0963721415599978.

Zaki, J., Ochsner, K.N., 2012. The neuroscience of empathy: progress, pitfalls and promise. Nat. Neurosci. 15, 675.

Zhan, Y., Xiao, X., Tan, Q., Zhang, S., Ou, Y., Zhou, H., Li, J., Zhong, Y., 2019. Influence of self-relevance and reputational concerns on altruistic moral decision making. Front. Psychol. 10, 1-10. https://doi.org/10.3389/fpsyg.2019.02194. 